Discussion Paper No. 18-057

Effects of Attribute-Based Regulation on Technology Adoption The Case of Feed-In Tariffs for Solar Photovoltaic

Robert Germeshausen

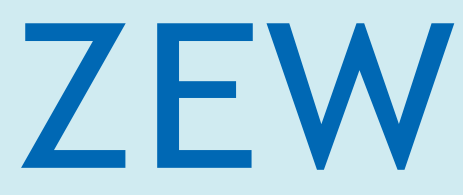

Zentrum für Europäische Wirtschaftsforschung $\mathrm{GmbH}$ Centre for European Economic Research 
Discussion Paper No. 18-057

\title{
Effects of Attribute-Based Regulation on Technology Adoption - The Case of Feed-In Tariffs for Solar Photovoltaic
}

\author{
Robert Germeshausen
}

Download this ZEW Discussion Paper from our ftp server:

http://ftp.zew.de/pub/zew-docs/dp/dp18057.pdf

Die Discussion Papers dienen einer möglichst schnellen Verbreitung von neueren Forschungsarbeiten des ZEW. Die Beiträge liegen in alleiniger Verantwortung der Autoren und stellen nicht notwendigerweise die Meinung des ZEW dar.

Discussion Papers are intended to make results of ZEW research promptly available to other economists in order to encourage discussion and suggestions for revisions. The authors are solely responsible for the contents which do not necessarily represent the opinion of the ZEW. 


\title{
Effects of Attribute-Based Regulation on Technology Adoption - The Case of Feed-In Tariffs for Solar Photovoltaic
}

\author{
Robert Germeshausen ${ }^{\mathrm{a}, \mathrm{b}, *}$ \\ ${ }^{a}$ Centre for European Economic Research, L 7, 1, 68161 Mannheim, Germany. \\ ${ }^{b}$ University of Münster, Center of Applied Economic Research Münster (CAWM), Am Stadtgraben 9, 48143 \\ Münster, Germany.
}

Version: 20 November 2018

\begin{abstract}
Feed-in tariffs are a widespread policy instrument to support the diffusion of renewable energy technologies. I investigate the impact of the size-based differentiation of these tariffs on the adoption of residential scale solar photovoltaic (PV) installations in Germany. Exploiting a policy change of administrative size classes for PV systems, I find that (i) the reduction in marginal feed-in tariffs decreases new capacity additions by around 29 per cent, and (ii) differentiated tariffs provide incentives for excess bunching at the ceiling of the smaller size class. Excess bunching decreases newly installed PV capacity additionally by around 14 per cent. Back-of-the-envelope calculations suggest that this may lead to annual efficiency losses that increase over time from about 0.2 to 4.4 per cent of the annual support cost for new small PV installations.
\end{abstract}

Keywords: Solar photovoltaic; feed-in tariffs; diffusion of renewable energy technologies; attribute-based regulation; bunching analysis

JEL classification: $\mathrm{O} 38, \mathrm{Q} 42, \mathrm{Q} 48$

\footnotetext{
* Corresponding author:

Email address: germeshausen@zew.de, +49 6211235218 (Robert Germeshausen)

I would like to thank Massimo Filippini, Ken Gillingham, Kathrine von Graevenitz, Koichiro Ito, Tooraj Jamasb, Andreas Löschel, Benjamin Lutz, Philipp Massier, Johannes Rode, Katrin Sommerfeld, and Ulrich Wagner for their helpful comments and suggestions. This work also benefited from discussions at the Annual Meeting of the Verein für Socialpolitik 2016, 6th AERE Summer Conference 2017, AURÖ Nachwuchsworkshop 2016, 22nd EAERE Annual Conference 2016, 9th International Workshop on Empirical Methods in Energy Economics 2016, 5th Mannheim Energy Conference 2016, and 21st Spring Meeting of Young Economists 2016 as well as from seminars at the ZEW Mannheim, University of Heidelberg and University of Münster. The data on regional end-use offer prices for electricity is kindly provided by ene't. The financial support by the German Federal Ministry of Education and Research (FKZ 03SFK4Z0) and by the Centre for European Economic Research (ZEW) Mannheim is gratefully acknowledged.
} 


\section{Introduction}

The diffusion of renewable energy technologies is regarded as one of the key measures for the mitigation of greenhouse gas emissions and for the transition towards a sustainable energy system. Governments across the globe have implemented various support measures to reap these potential benefits and to account for other (positive) externalities, such as increasing dynamic returns of technology adoption induced by learning-by-doing or learning-by-using effects (see e.g. Geroski, 2000; Jaffe et al., 2003, 2005). Recently, policy support and cost decreases triggered an expansion of renewable energy technologies in many parts of the world including Germany. While this development suggests that the support measures have been effective, it also underlines the need for rigorous evaluation of existing renewable energy policies.

Feed-in tariffs are a widely-used policy instrument to support the diffusion of renewable energy technologies. ${ }^{1}$ The producer receives a fixed price (feed-in tariff) for electricity generated from an eligible renewable energy technology and fed into the electricity grid. This tariff is in general higher than the average wholesale electricity price. Hence, it is a production subsidy. While the choice of the policy instrument to support renewable energy technologies certainly matters, its performance may also depend on specific design features that are common in existing policies. In Germany, the level of the feed-in tariff is differentiated based on characteristics or attributes of the renewable energy technology.

In this paper, I investigate how feed-in tariffs differentiated by individual system sizes for residential scale solar photovoltaic (PV) installations affect the adoption of these systems in Germany, using a quasi-experimental research design. Marginal feed-in tariffs for new rooftop solar PV installation depend on the size (i.e. power capacity) of the individual system. Smaller installation sizes receive a higher marginal feed-in tariff to reflect cost differences, with larger installations experiencing lower specific cost per installed capacity (e.g. due to fixed cost degression). Thereby, the marginal feed-in tariff is not a continuous function of size, but varies across administratively determined size classes. These size classes create discontinuities in the marginal feed-in tariff function (and kinks in the average feed-in tariff function) at the size class borders. These changes are unlikely to exactly represent (cost) differences across installation sizes, especially for small changes in installation sizes around the threshold values. The 2012 PV Amendment of the German Renewable Energy Sources Act ( $E E G$ ) includes a re-evaluation of size classes of PV installations and the introduction of a new size class for PV systems with a nominal capacity of up to 10 kilowatt (kW). This size differentiation reduces marginal feed-in tariffs for systems larger than $10 \mathrm{~kW}$ compared to the smaller ones. I show that, for size differentiation based on discrete size classes, this reduction

\footnotetext{
${ }^{1}$ In 2013, at the end of this paper's observation period, feed-in tariffs covered more than 70 per cent of the global PV market, being in place in countries such as China, Germany, Italy, and Japan, according to IEA (2014). In more recent years, this share has decreased but feed-in tariffs remain the predominant policy instrument with a share of more than 60 per cent in 2016 (IEA, 2017).
} 
in feed-in tariffs has two effects. First, a reduction in feed-in tariffs for larger systems reduces their profitability and consequently has a negative effect on newly installed capacity of these systems. Second, size differentiation based on fixed size classes also changes the distribution of system sizes that are built.

I estimate the impact of the reduction in marginal feed-in tariffs for larger scale residential systems on new capacity additions of these systems. The main identifying variation in feed-in tariffs for new installations over time and across size classes stems from the introduction of the new size class. Using bunching estimation methods (e.g. Saez, 2010; Chetty et al., 2011) and exploiting changes in the discontinuities of the marginal feed-in tariff function induced by this amendment, I find that the introduction of the new size class influences individual capacity choices in favour of smaller installation sizes just at the ceiling of the smaller size class (as evidenced by excess bunching).

I use data on all grid-connected solar PV installations with a nominal capacity of up to $20 \mathrm{~kW}$ in Germany that are supported by feed-in tariffs for the period between January 2009 and December 2013. This data stems from the renewable energy register collected by the four German transmission system operators and contains information about capacity, date of commission and postcodes of the individual installations. I conduct the analysis on the county (NUTS- $3^{2}$ ) level to better account for additional influencing factors varying at a regional level. ${ }^{3}$ Furthermore, I include data on regional end-use offer prices for electricity from ene't. During this time period, end-use electricity prices surpass feed-in tariffs for PV systems, providing an incentive to the owner to consume part of the electricity generated by the system instead of feeding it into the electricity grid.

I find that the reduction in marginal feed-in tariffs of about five percent for larger scale residential systems leads to a reduction in newly installed capacity of these systems by around 29 percent, while I control for excess bunching based on an approach similar to the one used by Best and Kleven (2018). Visual inspection and additional parametric analyses suggest that systems at the size class border would have been built larger in the absence of the introduction of the new size class. While installation costs are similar for systems close to the size class border, the introduction of the new size class leads to smaller and - in terms of support cost - to more expensive installations being built. I find that excess bunching decreases the newly installed capacity by around 14 per cent. This lower deployment level can be translated into higher support cost necessary to achieve an estimated counterfactual deployment level without the change in size classes. Back-of-the-envelope calculations suggest that this annual additional cost increases over time from initially about 0.2

\footnotetext{
${ }^{2}$ NUTS is the Nomenclature of Units for Territorial Statistics developed by the European Union. There are 402 counties in Germany.

${ }^{3}$ Solar PV deployment can be geographically heterogeneous due to different solar radiation values (Balta-Ozkan et al., 2015; Lamp, 2015), social learning (peer) effects (e.g. Gillingham and Bollinger, 2012; Graziano and Gillingham, 2014; Rode and Weber, 2016) and other socio-economic aspects (e.g. De Groote et al., 2016).
} 
up to 4.4 per cent of total annual support cost of the smaller size class, underlining the potential economic size of the distortions caused by this policy design change.

This paper contributes to the literature on the impact of policy instruments on the diffusion of solar PV installations (e.g. Kirkpatrick and Bennear, 2014; Hughes and Podolefsky, 2015; Crago and Chernyakhovskiy, 2017). While these studies focus on investment cost subsidy and loan programmes, there is a lack of rigorous empirical studies on the effects of feed-in tariffs on the diffusion of solar PV installations despite its wide use in existing support schemes. ${ }^{4}$ Several papers examine the relationship between the growth of solar PV deployment in Germany and investment incentives provided by feed-in tariffs (e.g. Leepa and Unfried, 2013; Grau, 2014; Ossenbrink, 2017). These analyses focus on showing correlations or simulating potential outcomes under different subsidy schemes but do not attempt causal inference. This paper intends to fill this gap.

This paper also contributes to the literature of differentiated (environmental) regulation. Besides spatially differentiated regulation (e.g. Tietenberg, 1978) and regulation differentiated by vintage of the respective technology (e.g. Gruenspecht, 1982; Nelson et al., 1993; Gray and Shadbegian, 2003; Stavins, 2006; Bushnell and Wolfram, 2012), regulations depending on other characteristics or attributes of the underlying technology have also come under scrutiny, most prominently for the case of fuel economy standards for cars (Klier and Linn, 2016; Ito and Sallee, 2018). ${ }^{5}$ I analyse the impact of a differentiated subsidy on the diffusion of PV systems. The question whether a technology-specific feed-in tariff (different for wind power, solar PV etc.) or a uniform, technology neutral feed-in tariff may be desirable is heavily debated (e.g. Requate, 2015; Lehmann and Söderholm, 2018). The differentiation of feed-in tariffs by installation size (within a technology) and its impact on technology adoption, however, has not received much attention so far. To the best of my knowledge, I am the first to investigate effects of size-based regulation on technology adoption for renewable energy technologies.

Furthermore, this paper is related to a more general literature inferring unobserved marginal cost of regulation from observed behaviour of economic agents (e.g. Anderson and Sallee, 2011; Meng, 2017). I estimate additional programme cost induced by differentiated feed-in tariffs from the observed changes in the distribution of installed PV system sizes.

The structure of the paper is as follows. Section 2 presents institutional details on the feed-in tariff system in Germany and the 2012 "PV Amendment" as well as a simple theoretical model of capacity choice, followed by the data description in Section 4. I specify the empirical strategy in Section 5. Section 6 presents the main results, while Section 7 concludes.

\footnotetext{
$\overline{{ }^{4} \text { Notable exceptions are Smith and Urpelainen }}$ (2014) and Carley et al. (2017). While the first use an instrumental variable approach to estimate the effect of feed-in tariffs on generation of renewable energy technologies on a crosscountry level, the latter uses a difference-in-differences strategy to compare renewable energy production in countries with and without feed-in tariff policies.

${ }^{5}$ Klier and Linn (2016) find that while fuel economy standards have increased the rate of technology adoption, producers reduced horsepower and torque in reaction to changes in these standards. Ito and Sallee (2018) evaluate weight-based fuel economy standards in Japan and show that this regulation leads to an increase in vehicle weight.
} 


\section{Policy Background: Solar PV Subsidies in Germany}

\subsection{The German Energiewende and Feed-in Tariffs for Renewable Energy Technologies}

In the course of its energy transition (Energiewende), Germany has set ambitious goals to increase the share of electricity generated by renewable energy technologies. For example, renewable electricity technologies should make up (at least) 80 per cent of gross electricity consumption in 2050 as stated in the Renewable Energy Sources Act $(E E G)$. Feed-in tariffs regulated under this law are one of the main policy instruments to foster the diffusion of renewable energy technologies in Germany. ${ }^{6}$ Within this system, eligible installations receive a fixed price (feed-in tariff) for every kilowatt hour $(\mathrm{kWh})$ of electricity that is fed into the electricity grid. The tariff is in general higher than the average wholesale electricity price and nominal tariffs for individual installations remain constant for 20 years beginning with the date of commission. The level of the feed-in tariffs is administratively determined, such that, on average, the operation of renewable installations is economically viable. This rationale has lead to a system of differentiated feed-in tariffs that are based on attributes of individual installations, such as the renewable technology, the plant type, and the installation size. Tariffs for newly installed systems are regularly adjusted (downwards) to reflect cost changes and technology developments over time. In addition to these regular adjustments, the federal government also intervened in the past to react to certain events, such as the unexpected pace of cost reductions for PV systems. All tariff adjustments only apply to new installations. Existing ones receive their initial fixed tariff, regardless of any changes after their commission.

For solar PV, feed-in tariffs are differentiated by size, i.e. peak power capacity of the system, and type, i.e. whether the installation is ground-standing or mounted on a rooftop. Marginal feed-in tariffs are not a continuous but a step function of installation size, i.e. they vary across administratively determined size classes. The feed-in tariff for an individual installation is given by the capacity-weighted average of the marginal feed-in tariffs (mixed calculation).

\subsection{The 2012 PV Amendment of the Renewable Energy Sources Act}

Since its introduction in 2000, the Renewable Energy Sources Act has been subject to several amendments. The so-called PV Amendment that came into force in April 2012 is specific as it includes a re-evaluation of the size classes relevant for the feed-in tariffs of solar PV installations as well as a further reduction of those tariffs. Before the enactment of the PV Amendment, size classes for solar PV were defined as follows: up to $30 \mathrm{~kW}$, larger than 30 up to $100 \mathrm{~kW}$, larger than $100 \mathrm{~kW}$ up to $1,000 \mathrm{~kW}$, and larger than 1,000 kW. Among other changes, the PV Amendment divides the smallest size class for rooftop installations (up to $30 \mathrm{~kW}$ ) into two size classes: up to $10 \mathrm{~kW}$ and larger than 10 up to $40 \mathrm{~kW}$. This change differentially affects marginal feed-in tariffs

\footnotetext{
${ }^{6}$ In recent years, there was a gradual shift from feed-in tariffs to "feed-in premium" mechanisms and tendering of support levels. However, for residential scale PV systems, which are the focus of this paper, feed-in tariffs are still the main policy instrument in place.
} 
for new residential scale installations of different capacity. In March 2012, the month before the PV Amendment, new installations up to $30 \mathrm{~kW}$ received a marginal feed-in tariff of 24.43 Euro cents per kWh. With the enactment of the PV Amendment in April 2012, the marginal feed-in tariff declined to 19.50 Euro cents per kWh for new installations up to $10 \mathrm{~kW}$ and to 18.50 Euro cents per $\mathrm{kWh}$ for new installations larger than $10 \mathrm{~kW}$ and up to $40 \mathrm{~kW}$.

A first draft of this amendment became known in February / March 2012, with subsequent political discussions about its content. After finally reaching an agreement in the German Conciliation Committee (Vermittlungsausschuss), the amendment was passed in June 2012 with effectiveness from April 2012. Before the draft of the PV Amendment reached the German Conciliation Committee, it specified size classes of up to $10 \mathrm{~kW}$ and larger than 10 to $100 \mathrm{~kW}$. The decision to include another size class for residential scale installations ranging from larger than 10 to $40 \mathrm{~kW}$ was made as one of the last adjustments. Given this political process and the retroactive enactment, the PV Amendment contained a protection clause. This clause permitted new installations to receive the older (and higher) tariffs that were valid before the PV Amendment, if the grid connection request had been filed by 24 February 2012 and if the installation was commissioned before July 2012 .

\subsection{The 2012 PV Amendment as a Quasi-Experiment}

Estimating the impact of feed-in tariffs on the installation of new PV systems presents several challenges. For example, feed-in tariffs are regularly adjusted downwards to reflect cost changes and technology development over time. The same factors affect the cost of adopting a new solar PV system and are therefore themselves drivers for deployment, hampering identification of the influence of feed-in tariffs.

To address these and similar concerns, I use variation in feed-in tariffs induced by the PV Amendment 2012 as a quasi-experiment. In particular, the PV Amendment affected residential scale PV systems, which I define throughout this paper as installations with a nominal capacity up to $20 \mathrm{~kW}$ in line with Borenstein (2017) and Ossenbrink (2017). In this paper, I focus on these residential scale PV systems to enhance comparability of installations. From 2009 until the enactment of the PV Amendment in 2012, new solar PV systems up to $20 \mathrm{~kW}$ represented about 70 per cent of all new solar PV installations, accounting for around 20 per cent of total new solar PV capacity in Germany. The PV Amendment introduced a new size class for systems up to $10 \mathrm{~kW}$ and thereby separated the level of marginal feed-in tariffs for these installations from larger systems.

In the following I distinguish two groups: larger scale residential systems, i.e. with a nominal capacity larger than $10 \mathrm{~kW}$ and up to $20 \mathrm{~kW}$, are in the treatment group; smaller installations (up to $10 \mathrm{~kW}$ ) act as the control group. As depicted in Figure 1, new larger scale residential systems experienced a stronger reduction in the marginal feed-in tariff of about five percent compared to smaller systems with the start of the PV Amendment in April 2012. 


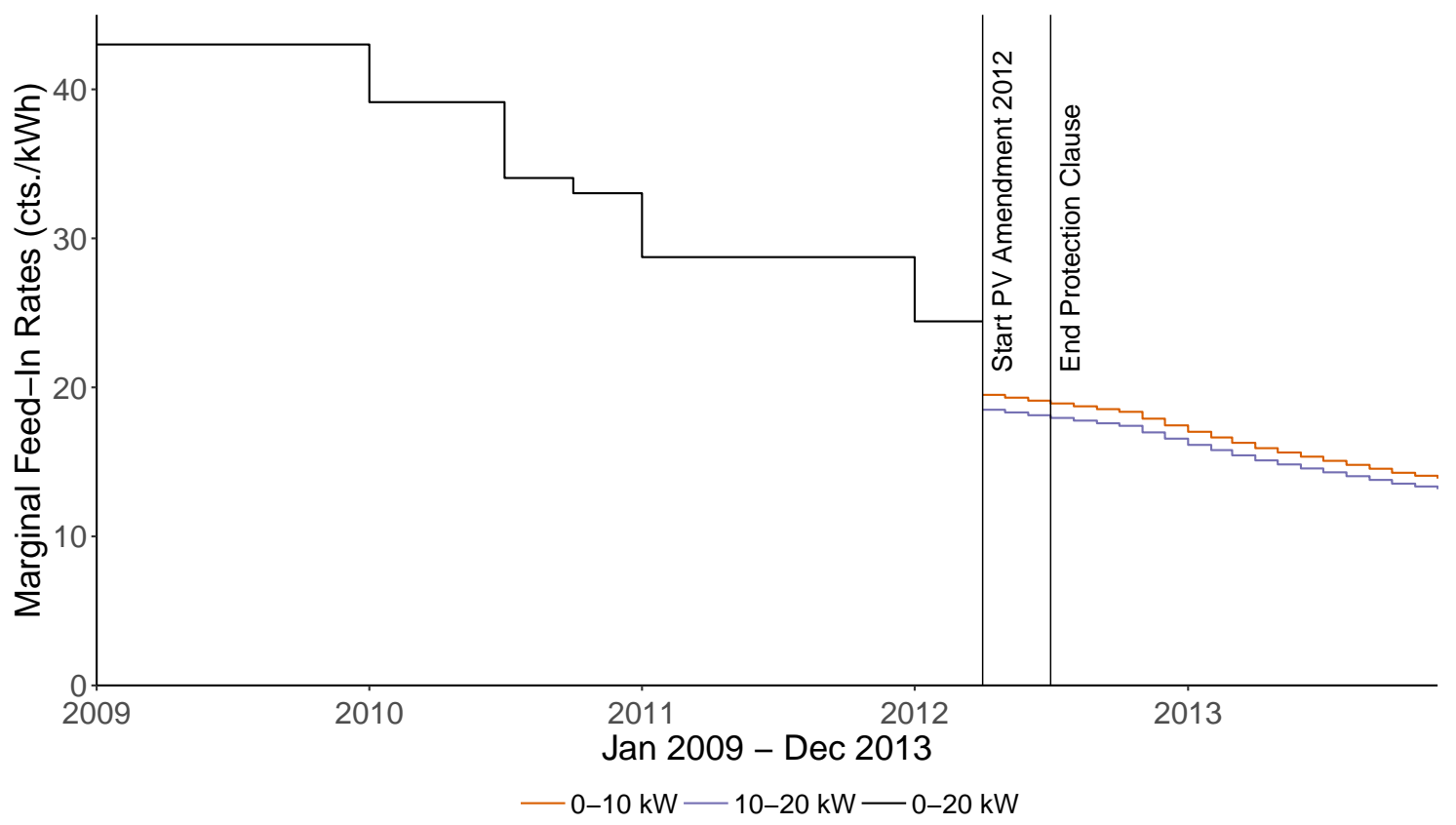

Figure 1: Marginal Feed-in Rates for Residential Scale Rooftop Solar PV Installations

Notes: The black solid line depicts the development of marginal feed-in rates in the smallest size class for rooftop solar PV installations (up to $30 \mathrm{~kW}$ ) until the PV Amendment in April 2012, which is represented by the first vertical line. The second vertical line denotes the end of the protection clause period in July 2012. From April 2012, the downward sloping solid orange line depicts the development of the marginal feed-in tariff up to $10 \mathrm{~kW}$, while the solid purple line shows the marginal feed-in tariffs of the relevant size class (larger than 10 to $40 \mathrm{~kW}$ ) for installations between 10 and $20 \mathrm{~kW}$. The data for the feed-in tariff levels stems from the German Federal Network Agency (BNetzA, 2016).

Figure 2 depicts the development of monthly capacity additions of new solar PV installations for installation sizes up to $10 \mathrm{~kW}$ and from larger than 10 up to $20 \mathrm{~kW}$ on a national level from the beginning of 2009 until the end of 2013. The spikes in deployment coincide with the month before a downward adjustment of feed-in tariffs takes place and reflect anticipation effects as described by Leepa and Unfried (2013) and Grau (2014). The development of new capacity additions for both size classes evolves similarly, especially from mid year 2010 on until the start of the PV Amendment in April 2012, which is depicted by the first vertical line in Figure 2. The second vertical line in Figure 2 marks the end of the protection clause in July 2012.

The national figures imply a divergence of new capacity additions in both size classes coinciding with the enactment of the PV Amendment and the end of the protection clause, respectively. Before the PV Amendment, aggregated newly installed capacity of smaller installations was less than the capacity of larger scale residential systems in every month. After the PV Amendment the smaller installations experienced higher monthly capacity additions than larger systems. 


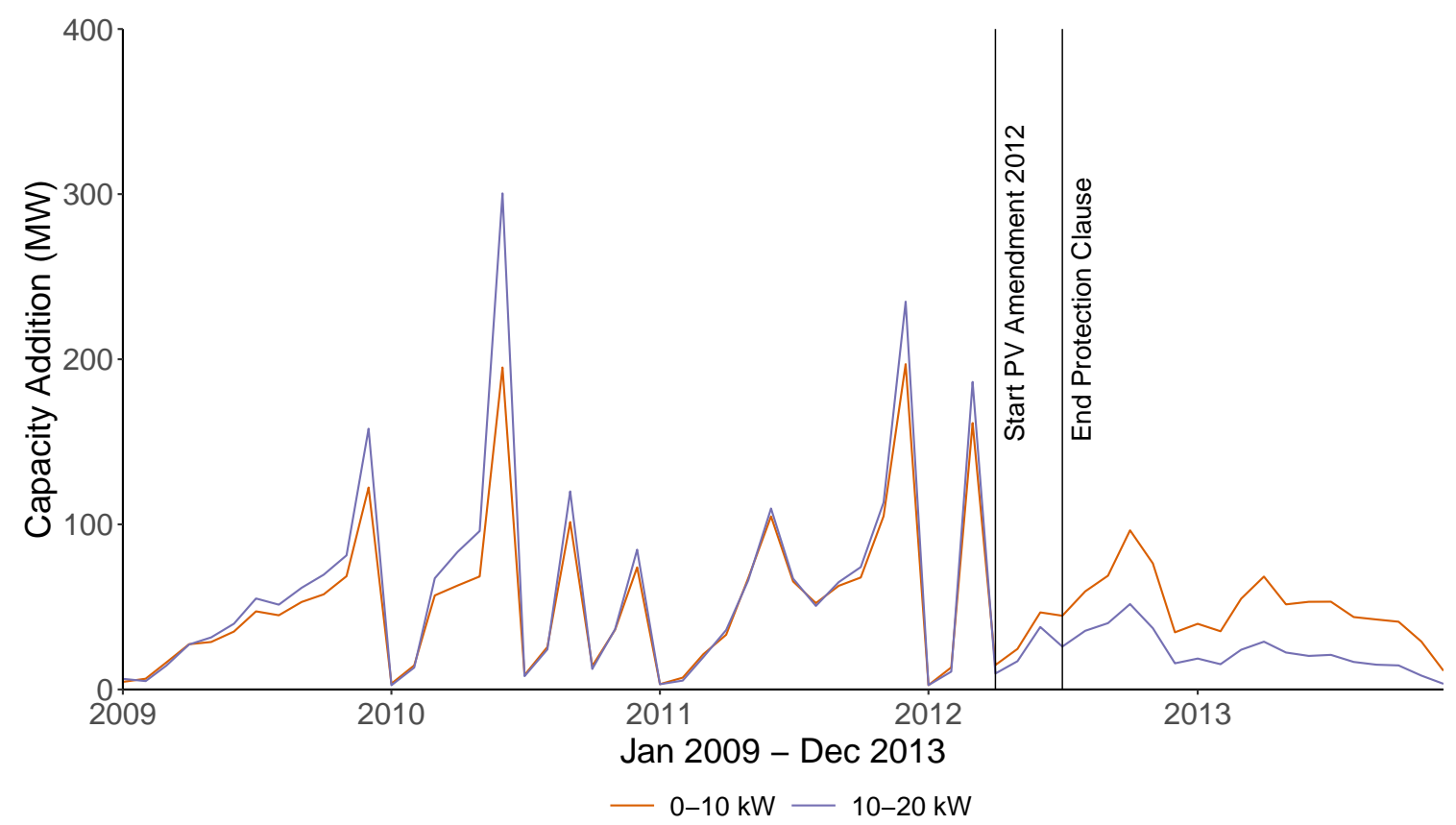

Figure 2: Monthly Deployment of New Solar PV Capacity

Notes: The solid orange line depicts the aggregated monthly new capacity additions of new solar PV installations up to $10 \mathrm{~kW}$, while the solid purple line represents the monthly deployment of capacity from systems larger than $10 \mathrm{~kW}$ and up to $20 \mathrm{~kW}$. The first vertical line depicts the PV Amendment in April 2012, while the second vertical line shows the end of the protection clause in July 2012. Own illustration based on data from the four German transmission system operators (ÜNB, 2014).

The distribution of capacity additions across system sizes is different after the enactment of the PV Amendment. While these changes can be seen in Figure 2 as more capacity in the smaller size class is being built compared to the larger one, the distribution of the capacity shares of new PV installations across system sizes reveals additional noteworthy patterns at the border of size classes. ${ }^{7}$ Figure 3 shows the capacity shares of newly installed systems within one $\mathrm{kW}$ bins up to $20 \mathrm{~kW}$ within one year (from July to December) and in the previous year (from July to December). ${ }^{8}$ Before the PV Amendment, the distribution appears to be stable across years. After the change in size classes in 2012, a spike at the $10 \mathrm{~kW}$ bin is striking. New installations bunch just below the capacity threshold for the lower marginal feed-in tariff. The comparison between the distributions in 2011 and 2012 indicates a shift from larger to smaller installations around the threshold value since the relative drop from 2011 to 2012 only occurs for bins larger than $10 \mathrm{~kW}$ and most prominently for bins slightly larger than this threshold. This pattern suggests that some

\footnotetext{
${ }^{7}$ I use shares instead of absolute capacity additions to facilitate comparison across years.

${ }^{8} \mathrm{I}$ compare the installations within these months in order to control for possible seasonal effects. July 2012 is the first month after the end of the protection clause. The same pattern appears when I use data from April to December in each year and compare aggregates before and after the enactment of the PV Amendment (without taking potential seasonal effects into account).
} 
PV installations in the size class up to $10 \mathrm{~kW}$ would have been built larger without the introduction of a new size class.

a) 2009 vs. 2010

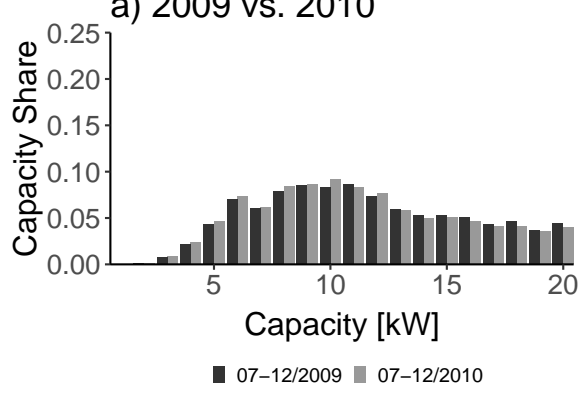

c) 2011 vs. 2012

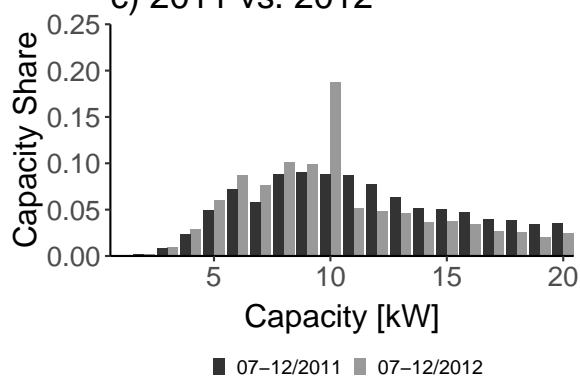

b) 2010 vs. 2011

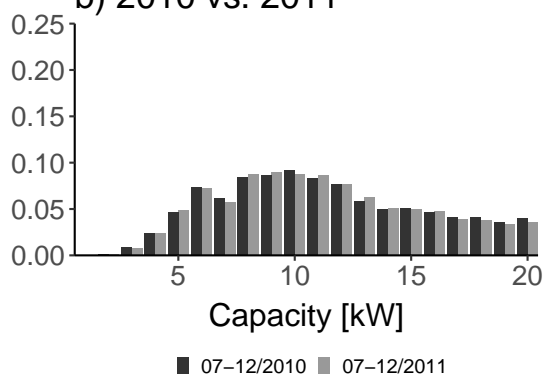

d) 2012 vs. 2013

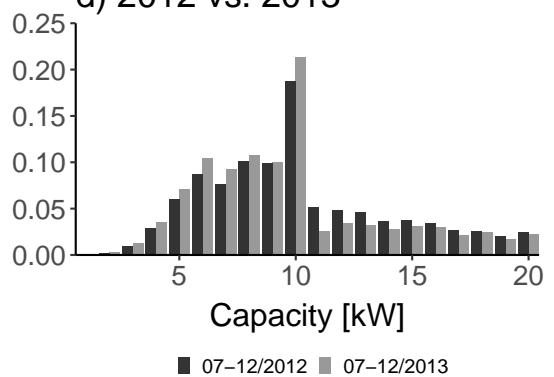

Figure 3: Distribution of Individual Installations in a Year-on-Year Comparison

Notes: The height of each bar reflects the share of newly installed capacity within each one $\mathrm{kW}$ bin in total installed capacity up to $20 \mathrm{~kW}$ during the specified time period. The black bar denotes the previous year, whereas the grey bar represents the following year. Own illustration based on data from the four German transmission system operators (ÜNB, 2014).

Additionally, the PV Amendment introduced more frequent regular adjustments of the level of feed-in tariffs (from annual to monthly frequency based on historical deployment) ${ }^{9}$, a limit of 90 per cent compensation for installations larger than $10 \mathrm{~kW}$ at the beginning of 2014, and an overall $52 \mathrm{GW}$ threshold on total cumulated PV installation capacity regulated under the EEG. Once cumulated PV capacity reaches this threshold, the feed-in system for new PV installations would be stopped. Furthermore, the amendment added the technical requirement that all PV systems (existing and new ones) must be able to curtail production. From these additional changes, the limit of 90 per cent compensation for larger scale residential PV systems appears to be important for this paper as it potentially further reduces subsidies for larger installations. ${ }^{10}$ Installations that were commissioned after March 2012 and that were larger than $10 \mathrm{~kW}$ have received feed-in tariffs for only 90 per cent of the produced electricity from January 2014 onwards. From this time

\footnotetext{
${ }^{9}$ This is likely to be one of the reasons that there are no more pronounced deployment spikes in Figure 2 after the PV Amendment.

${ }^{10}$ Regarding the technical requirement to curtail production, PV systems up to $30 \mathrm{~kW}$ could alternatively restrict maximum electricity feed-in to 70 per cent of their (peak) capacity. Therefore, this change did not introduce an additional differential treatment of residential scale PV systems.
} 
on, 10 per cent of the electricity production has had to be either sold privately or self-consumed. This change could potentially further decrease the effective feed-in tariff for larger installations that already receive the lower nominal feed-in tariff. However, this change should not provide a massive disadvantage for larger installations since households should technically be able to achieve these self-consumption rates (e.g. ZSW, 2014). Furthermore, self-consumption in this period is also economically favourable as residential end-use electricity prices surpass the feed-in tariff level for both size classes. ${ }^{11}$

\section{Theory: A Model of Capacity Choice}

To better understand the individual behaviour underlying the aggregated figures presented in Figure 2 and 3 and the changes introduced by the PV Amendment, I develop a simple model of capacity choice of households for new installations. I abstract from the timing decision of adoption but restrict the model to the problem of choosing the system size conditional on adopting. ${ }^{12}$

Households maximize quasi-linear utility $U$ subject to their budget constraint. The decision variables for the individual household $i$ are the capacity of the PV system $\left(k_{i}>0\right)$ and consumption of a numeraire good $x_{i}$ with constant marginal utility: $U_{X, i}=x_{i}$. The utility from a solar PV installation $U_{P V}\left(k_{i}\right)$ depends on the capacity size and is represented by the present value for $T$ periods of revenue stream. ${ }^{13}$ The (expected) discounted revenue of the PV system over its lifetime under (pure) feed-in tariff regulation equals $\sum_{t=1}^{T} \beta_{i}^{t}\left(k_{i} \times F I T\left(k_{i}\right) \times H_{i}\right)$, where $\beta_{i}$ is the individual discount factor, $\operatorname{FIT}\left(k_{i}\right)$ is the average feed-in tariff for system size $k_{i}$ that is valid at the time of adoption, and $H_{i}$ is the (expected) number of full-load hours / normalized irradiation values. ${ }^{14}$

Households maximize utility by choosing the capacity of their PV system $k$ and consumption of the numeraire good $x$ subject to their budget constraint:

$$
\begin{aligned}
\operatorname{Max}_{k_{i}, x_{i}} & U_{i}=U_{P V}\left(k_{i}\right)+U_{x}\left(x_{i}\right) \\
\text { s.t. } & I_{i} \geq C_{i}\left(k_{i}\right)+x_{i},
\end{aligned}
$$

\footnotetext{
${ }^{11}$ Since electricity generation profiles from solar PV and household consumption profiles do not overlap perfectly and there were few systems connected with battery storage at this time, the share of self-consumption is nevertheless lower than 100 per cent. In Section 6.3, I discuss how the interpretation of the results would change, if the apparent bunching is driven by the 90 per cent compensation limit.

${ }^{12}$ The actual decision to adopt or not adopt in a given period is a dynamic problem, which is addressed for example in Alizamir et al. (2016) and Feger et al. (2017). In this subsection, however, the focus is on the choice of the system size. This choice can be regarded as a decision in a second stage after the (dynamic) decision to adopt a solar PV system has been made.

${ }^{13}$ In principle, the model extends to cases where additional factors that influence individual utility from a PV system, such as environmental preferences, enter in a linear fashion. These factors would introduce another source of heterogeneity across different households but would not impact the analysis of capacity choices of a single household under different feed-in tariff regimes.

${ }^{14}$ Appendix A contains a model extension allowing for consumption of self-generated electricity from the PV system instead of feeding the whole amount into the electricity grid. This self-consumption is economically attractive, if residential electricity prices are larger than feed-in tariffs.
} 
where $I_{i}$ represents income and $C_{i}\left(k_{i}\right)$ describes the total cost of installing a PV system (including the system price, installation cost, necessary permits etc.) as well as (discounted) operation and maintenance cost. The cost function is increasing in system size and is twice-differentiable until the capacity reaches the limit of the rooftop. I assume constant marginal cost in the segment until the rooftop limit and infinite marginal cost thereafter, reflecting the potential cost of extending the roof or moving to a new house. ${ }^{15}$ Using the assumption of constant marginal utility of $x$, the budget constraint can be included in the objective function as below:

$$
\operatorname{Max}_{k_{i}} U_{i}=U_{P V}\left(k_{i}\right)+I_{i}-C_{i}\left(k_{i}\right)
$$

Maximizing this function with respect to capacity $k_{i}$ yields the familiar first order condition of marginal benefits equalling marginal cost, indicating optimal capacity $k_{i}^{*}$ :

$$
\begin{aligned}
\frac{\partial U_{i}}{\partial k_{i}}: \frac{\partial U_{P V}}{\partial k_{i}}-\frac{\partial C_{i}}{\partial k_{i}} & =0 \\
\frac{\partial U_{P V}}{\partial k_{i}} & =\frac{\partial C_{i}}{\partial k_{i}}
\end{aligned}
$$

Under a uniform feed-in tariff, the marginal feed-in tariff does not depend on the capacity choice, i.e. $F I T\left(k_{i}\right)=F I T_{1}$. With attribute-based (size-based) regulation with fixed size classes, as in Germany, the marginal feed-in tariff is a piecewise function of capacity $k$, where the marginal feed-in tariff is smaller for the larger size class, i.e. $F I T_{2}=F I T_{1}-d$, where $d$ indicates the decrease in marginal tariffs. For a tariff structure with two size classes (up to $k^{\prime}$ and larger than $k^{\prime}$ ), the average feed-in tariff is as follows: ${ }^{16}$

$$
F I T\left(k_{i}\right)=\left\{\begin{array}{ll}
F I T_{1}, & \text { for } k_{i} \leq k^{\prime} \\
F I T_{1}-\left(1-\frac{k^{\prime}}{k_{i}}\right) d, & \text { for } k^{\prime}<k_{i}
\end{array}\right\}
$$

Marginal benefits are piecewise constant but the specification of the size class determines the marginal benefit of the individual system:

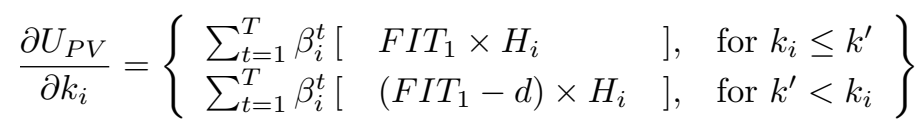

Threshold values at the boundaries of size classes create kinks in the feed-in tariff function. Therefore, a major impact of the introduction of different marginal feed-in tariffs across size classes can be expected for larger system sizes as marginal benefits drop discretely. This discrete change may offer one explanation for the excess bunching at the ceiling of the lower size class that can be observed in the data after the introduction of attribute-based regulation for residential scale PV systems.

\footnotetext{
${ }^{15}$ Constant marginal cost is only assumed for ease of illustration in Figure 4. The model extends to positive but decreasing marginal cost, reflecting economies of scale as found by e.g. Gillingham et al. (2016), in the segment until the rooftop limit is reached.

${ }^{16}$ For $k^{\prime}<k_{i}$, the expression of the average feed-in tariff is a transformation of the capacity weighted average of the form $k^{\prime} / k \times F I T_{1}+\left(k-k^{\prime}\right) / k \times F I T_{2}$.
} 


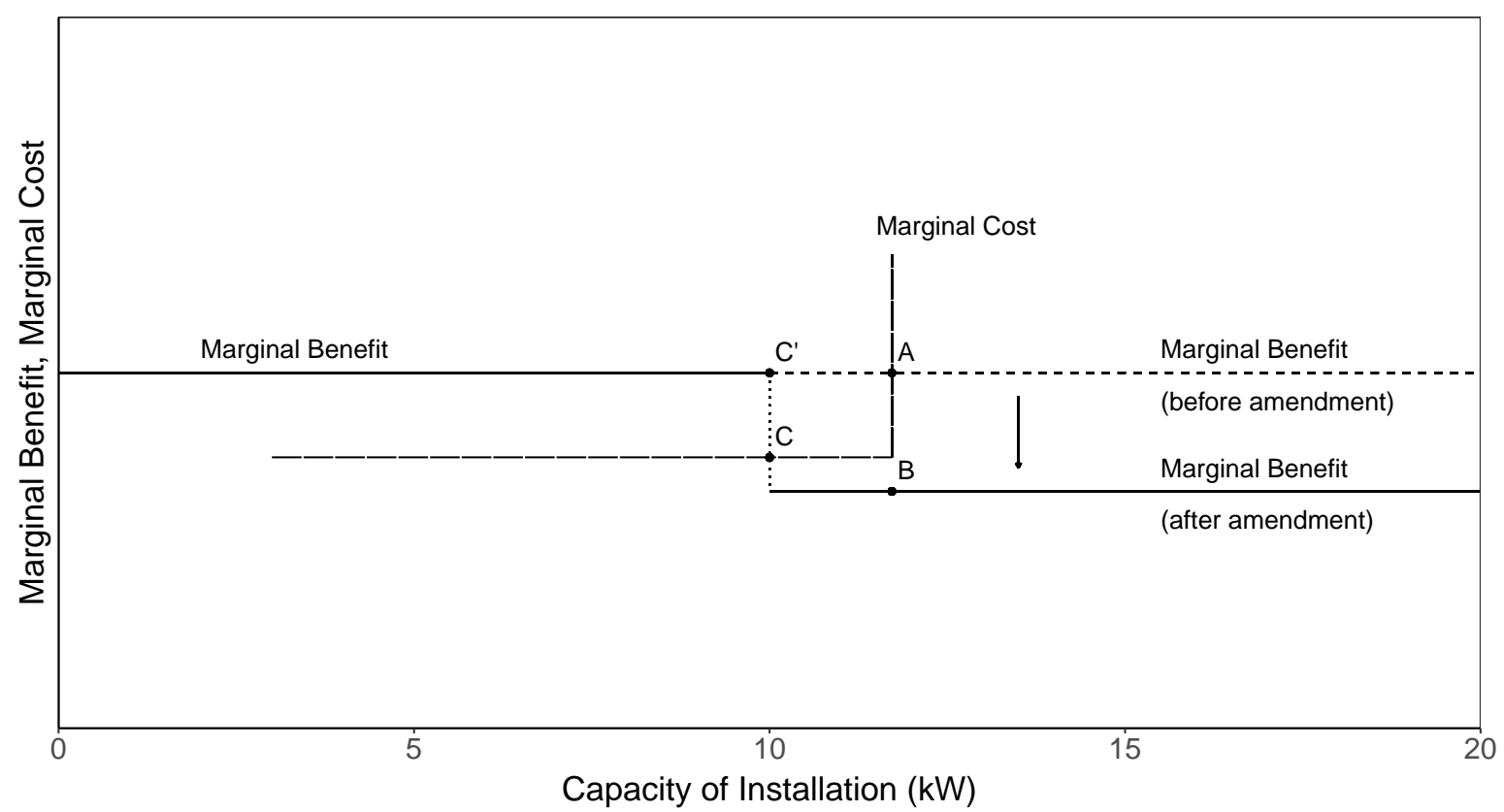

Figure 4: Bunching after Re-evaluation of Size Classes for FIT $>P$

Figure 4 depicts a marginal cost function, which is constant until the rooftop threshold is hit (in this case at $12 \mathrm{~kW}$ ) and increases infinitely thereafter, as well as the piecewise constant marginal benefit function (in line with the definition of size classes within the PV Amendment 2012, i.e. $k^{\prime}=10 \mathrm{~kW}$ ). This figure illustrates an exemplary individual capacity decision for a specific point in time. Before the PV Amendment, all installations up to $20 \mathrm{~kW}$ received the same marginal feed-in tariff. In this example, this specific household would optimally install the related capacity at point A. However, with the feed-in tariff scheme in place after the PV Amendment, the capacity choice at point $\mathrm{A}$ is no longer feasible but replaced by point $\mathrm{B}$. The household maximizes utility at point C, respectively point C', which is directly at the upper bound of the smaller installation category. Since this threshold is the same for all households, this effect can lead to excess bunching of installations at a capacity of $10 \mathrm{~kW}$.

In this model, optimal individual capacity choice depends on several factors, some of which are the same for all adopters, while others are household specific:

$$
k_{i}^{*}=f\left(\beta_{i}, F I T, H_{i}, M C_{i}\right) .
$$

More specifically, optimal individual capacity choices are determined by the discount factor $\beta_{i}$, the (expected) normalized solar irradiation / full-load hours $H_{i}$ as well as marginal cost $M C_{i}$ (all these factors can be heterogeneous across households) and the feed-in tariff regime FIT, which 
applies to every household. The individual decisions on the installation size can be aggregated over all households $J$ to obtain total capacity in the different size classes:

$$
K_{0}=\sum_{i}^{J} k_{i} \mathbb{1}\left[k_{i} \leq k^{\prime}\right] \quad \vee \quad K_{1}=\sum_{i}^{J} k_{i} \mathbb{1}\left[k_{i}>k^{\prime}\right],
$$

where $K_{0}$ and $K_{1}$ are aggregate capacity in the smaller and in the larger size class, respectively.

\section{Data}

I use data on the universe of grid-connected solar PV installations supported by feed-in tariffs in Germany for the period between January 2009 and December 2013. This data stems from the renewable energy register collected by the four German transmission system operators (ÜNB, 2014) and provides information on e.g. the size (nominal peak capacity) of the individual installation, its date of commissioning as well as the post code area in which the system was installed. The capacity of the individual installation and the month of commission determine each individual system's feed-in tariff. I assign postcode areas to all 402 German counties (NUTS-3) based on information provided by ene't. I aggregate the capacity of new installations at the county level with monthly frequency for two size classes: up to $10 \mathrm{~kW}$, and larger than 10 up to $20 \mathrm{~kW}$.

Data on regional end-use offer prices for electricity are provided by ene't (2014). I aggregate individual offer prices by computing the average of all available offer prices for the energy component (kilowatt hour rate) for each county and every month. I restrict offers to be for households and exclude special rates (e.g. block pricing, rates for electric heating). One shortcoming of using offer prices is the lack of information on the exact prices individuals actually pay. Unfortunately, this information is not available at the county level. The data at hand include a complete list of all offer prices published by utilities in a region and at a specific time. Therefore, these offer prices capture regional as well as time variation of actual end-use electricity prices and of electricity prices that are potentially available to households. 
Table 1: Descriptive Statistics

January 2009 - December 2013

\begin{tabular}{lccccc}
\hline \hline Variable & Mean & Std. Dev. & Min. & Max. & N \\
\hline New capacity additions $[\mathbf{k W}]$ & & & & & \\
$\quad$ of all systems up to $20 \mathrm{~kW}$ & 126.497 & 222.725 & 0 & $6,271.400$ & 48,240 \\
$\quad$ in size class up to $10 \mathrm{~kW}$ & 129.705 & 176.665 & 0 & $2,858.300$ & 24,120 \\
$\quad$ in size class $>10$ up to $20 \mathrm{~kW}$ & 123.288 & 260.736 & 0 & $6,271.400$ & 24,120 \\
End-use offer prices [EUR cts./kWh] & 20.06 & 1.80 & 16.18 & 25.25 & 48,240 \\
\hline \hline
\end{tabular}

Before April 2012 (January 2009 - March 2012)

\begin{tabular}{lccccc}
\hline \hline Variable & Mean & Std. Dev. & Min. & Max. & N \\
\hline New capacity additions $[\mathrm{kW}]$ & & & & & \\
$\quad$ of all systems up to $20 \mathrm{~kW}$ & 147.745 & 263.279 & 0 & $6,271.400$ & 31,356 \\
$\quad$ in size class up to $10 \mathrm{~kW}$ & 136.398 & 201.643 & 0 & $2,858.300$ & 15,678 \\
$\quad$ in size class $>10$ to $20 \mathrm{~kW}$ & 159.091 & 312.600 & 0 & $6,271.400$ & 15,678 \\
End-use offer prices $[\mathbf{E U R}$ cts./kWh] & 19.00 & 0.92 & 16.18 & 25.25 & 31,356 \\
\hline \hline
\end{tabular}

After June 2012 (July 2012 - December 2013)

\begin{tabular}{lccccc}
\hline \hline Variable & Mean & Std. Dev. & Min. & Max. & N \\
\hline New capacity additions [kW] & & & & & \\
of all systems up to $20 \mathrm{~kW}$ & 91.328 & 106.870 & 0 & $1,243.481$ & 13,668 \\
in size class up to $10 \mathrm{~kW}$ & 125.745 & 125.745 & 0 & $1,243.481$ & 6,834 \\
in size class $>10$ to $20 \mathrm{~kW}$ & 56.912 & 76.665 & 0 & $1,013.250$ & 6,834 \\
End-use offer prices [EUR cts./kWh] & 22.39 & 1.19 & 19.68 & 24.29 & 13,668 \\
\hline \hline
\end{tabular}

Notes: Observations are on the county-month-size-class level. Data for new capacity additions and electricity price offers stems from ÜNB (2014) and ene't (2014), respectively. End-use offer prices refer to the average end-use offer prices for the energy component (kilowatt hour rate) in each county and month.

The descriptive statistics provided in Table 1 give an overview of the main variables used in this analysis. The average monthly capacity addition within a county in both size classes during the whole study period is around $127 \mathrm{~kW}$, while the minimum is zero and the maximum is around 6.3 Megawatt (MW). Furthermore, I split up the descriptive statistics by time period (overall, before and after the PV Amendment) and by size class. Before April 2012, the monthly capacity additions of systems up to $10 \mathrm{~kW}$ are on average smaller than those for installations in the larger size class. After the enactment of the PV Amendment and the end of the protection clause in July 2012 , this pattern reverses, with installations up to $10 \mathrm{~kW}$ displaying on average larger monthly capacity additions. The average regional offer prices vary during the whole period between around 16 and 25 Euro cents per $\mathrm{kWh}$, with a mean of around 20 Euro cents per $\mathrm{kWh}$. Compared to the average residential end-use electricity prices of the "default" price of the regional basic suppliers, which amount to 30.11 (April 2013), 26.61 (April 2012), and 25.88 (April 2011) Euro cents per 
kWh, respectively (BNetzA-BKartA, 2013); the offer prices for the energy component only are considerably lower. ${ }^{17}$

\section{Empirical Strategy}

To investigate the effects of size-based differentiation of feed-in tariffs for residential scale solar PV systems on the adoption of theses systems, my empirical strategy comprises two parts, which are explained in detail in Sections 5.1 and 5.2. First, observing the difference in new capacity additions between the larger size class (treatment group) and the smaller size class (control group) before the amendment (under uniform tariffs) and after the amendment (under differentiated feed-in tariffs) is key for identification. This variation over time and across size classes as well as a large set of fixed effects enables me to identify the effect of the change in feed-in tariffs on new deployment for the larger size class. One of the underlying assumptions is that the choice of the size class definition and the threshold value at $10 \mathrm{~kW}$ is "as good as random". The annual distributions of installations from 2009 to 2011 depicted in Figure 3 show no pattern of a separation at $10 \mathrm{~kW}$ that would point to other discretely changing conditions at this threshold, such as typical roof sizes or financing packages. Furthermore, IE Leipzig (2011) reports only small cost differences at this size class border. ${ }^{18}$

Second, while the regulator's choice of the threshold value may be assumed to be "as good as random", it does not guarantee that the variation in feed-in tariffs from the PV Amendment is exogenous. With the introduction of the new size class, investors can choose their marginal feed-in tariff indirectly through their capacity choice. ${ }^{19}$ Using the discontinuity in marginal feed-in tariffs and bunching analysis, I estimate the extent of this self-selection (evident from excess bunching at the size class border). Similar to the approach of Best and Kleven (2018), I adjust new capacity additions by the bunching estimates to control for self-selection into the smaller size class. Using this adjustment, I estimate the empirical equation outlined in Section 5.1 to identify the effect of the reduction in marginal feed-in tariffs on capacity additions in the larger size class. Furthermore, I reestimate this specification for different bunching adjustments to analyse the additional deployment effect caused by self-selection under size-based regulation with discrete size classes.

\subsection{Estimation of Average Treatment Effect on Deployment}

I use variation in deployment in the two size classes before and after the PV Amendment to investigate the impact of a reduction in feed-in tariffs on the deployment of new PV systems. The dependent variable is new capacity additions within one of the two size classes in each county and

\footnotetext{
${ }^{17}$ These defaults prices also include the fixed part of the end-use electricity price, while the offer prices only capture the energy component. Although the default price is among the most expensive tariff options, around one-third of all residential customers have a default tariff at their regional supplier in 2012 (BNetzA-BKartA, 2013).

${ }^{18} \mathrm{I}$ also show that these differences do not change discretely at the size class border in Section 6.3 .

${ }^{19}$ The theoretical model in Section 3 makes this mechanism explicit.
} 
month. This variable can take either positive values or zero. For 15 per cent of all observations the dependent variable is zero. These occur mainly in months after an adjustment in feed-in tariffs and are likely a consequence of anticipation effects of investors.

The theoretical model in Section 3 presents several influencing factors for the deployment of new PV systems that may vary across regions, size-classes and over time. To account for constant differences along those dimensions and to isolate the impact of the PV Amendment, the empirical specification relies on a number of fixed effects. First, I include county-size-class fixed effects to capture time constant differences in deployment between the two size classes, allowing them to vary on the regional level. Larger installations have smaller specific cost per unit capacity due to fixed cost degression. IE Leipzig (2011) provides evidence that there are cost differences, but that these are small for residential scale systems. Furthermore, county-size-class fixed effects capture time constant differences in regional deployment of smaller and larger installations, which may be driven by e.g. different building structures across regions. Building structure is likely to be a crucial determinant of deployment as the installation decision and the system size is dependent on the space available, i.e. the rooftop size. Given the short time period of this study, building structure may be regarded as fixed and captured by county-size-class fixed effects.

Second, I include month-year fixed effects to account for time effects that are the same for all regions and installation sizes. It includes e.g. the general regulatory environment from the federal government, general (macroeconomic) conditions and technological progress in the solar PV industry. ${ }^{20}$

Third, county-year fixed effects control for time constant differences across regions as well as year-on-year changes in (unobservable) characteristics. As data on socio-economic characteristics like income and population is only observed at the regional level at annual frequency (for example from the INKAR database) the county-year fixed effects would absorb this variation. Therefore, I do not explicitly include these variables in the empirical model.

The various fixed effects control for influences that remain constant over time, are the same for all counties or vary at the county level with annual frequency. One potential additional important variable that exhibits within-year variation at the regional level are end-use electricity prices. $^{21}$ One potential concern is that residential electricity prices have surpassed the level of feed-in tariffs (grid parity) during this time period. While electricity offer prices (ene't, 2014) suggest that grid parity occurred simultaneously with the enactment of the PV Amendment, average actual residential electricity prices (Eurostat, 2018) surpassed feed-in tariffs even before. Grid parity

\footnotetext{
${ }^{20}$ The latter is only true under the assumption that technological progress does not differ for installation sizes up to $20 \mathrm{~kW}$. Figures from Benedetti (2014) suggest that module and inverter prices for different installation sizes experienced similar developments in the recent past. More details about the development of cost differences can be found in Appendix D.

${ }^{21}$ The average offer price for the energy component changes in 55 per cent and the minimum offer price in 22 per cent of all observations across subsequent months. Assuming the price would only change once a year, the price would change in only seven per cent of all observations.
} 
provides incentives to owners of PV systems to consume part of the self-generated electricity, which decreases the gap in marginal benefits between both size classes under differentiated tariffs. ${ }^{22}$ If selfconsumption becomes relevant for owners of a new PV system, the identified effect is a conservative estimate of a five per cent reduction in marginal benefits. ${ }^{23}$ Furthermore, I explicitly account for differences in the profitability of self-consumption across regions and time by including time-varying regional end-use electricity offer prices for the energy component as a control variable.

The large number of zeros in the dependent variable and the various fixed effects resemble those characteristics encountered in the trade literature on the estimation of gravity equations explaining trade between country pairs. Therefore, for the empirical approach, I borrow a nowadays standard estimator in this field, namely the Poisson Pseudo-Maximum Likelihood (PPML) estimator as suggested by Santos Silva and Tenreyro (2006). The authors advocate the use of PPML instead of log-linearised models. ${ }^{24}$ While the application in this paper is different, key characteristics of the data and the preferred model specification are similar to the gravity equation setting. ${ }^{25}$ The formulation of the empirical model is as follows:

$$
\Delta K_{i, m, y, r}=\exp \left(\alpha+\mu_{i, r}+\mu_{m, y}+\mu_{i, y}+\beta D_{m, y, r}+\gamma X_{i, m, y}\right) \epsilon_{i, m, y, r},
$$

where $\Delta K_{i, m, y, r}$ denotes the capacity additions in county $i$ in month $m$ in year $y$ within size class $r(\leq 10 \mathrm{~kW}$ or $>10$ and $\leq 20 \mathrm{~kW}) . \mu_{i, y}, \mu_{i, r}$, and $\mu_{m, y}$ are county-year, county-size-class, and month-year fixed effects, respectively. $D_{m, y, r}$ is a binary variable and equals one for deployment within the larger size class after the enactment of the PV Amendment. $\beta$ is the parameter of interest indicating the average effect of the reduction in marginal feed-in tariffs for the treatment group (larger residential scale systems). $X_{i, m, y}$ denotes the monthly average end-use electricity offer prices for the energy component in the respective county area and $\exp ($.$) is the exponential$ operator. $\epsilon_{i, m, y, r}$ is the error term. ${ }^{26}$

\subsection{Self-Selection and Estimation of Excess-Bunching}

A visual inspection of Figure 3 suggests that excess bunching of new installations occurred after the enactment of the PV Amendment as investors chose their installation size, given the new regulation. If such self-selection is neglected, it will be implicitly assigned to the negative deployment effect of

\footnotetext{
${ }^{22}$ I use an extension of the theoretical model to derive this result in Appendix A.

${ }^{23}$ I control for regional offer prices in the empirical specification as discussed in Section 5.1.

${ }^{24}$ The underlying data generating process is not restricted to a Poisson distribution for consistency of the Poisson Pseudo- or Quasi-Maximum Likelihood estimator. Consistency holds if the conditional mean function, in this case $\mathrm{E}[y \mid x]=\exp \left(x^{\prime} \beta\right)$, is correctly specified, where $y$ is the dependent variable, $x$ are the independent variables of the model, and $\beta$ are the coefficients to be estimated. Furthermore, the dependent variable does not have to be a count variable but must be non-negative (Cameron and Trivedi, 2013).

${ }^{25}$ Götzke and Rave (2016) analyse the expansion of wind energy installations in Germany, using the PPML estimator.

${ }^{26}$ I cluster standard errors in all regressions at the county-class level. Standard errors clustered at the county level to account for serial correlation at the higher level (Bertrand et al., 2004) were consistently smaller than county-class clustered standard errors. To be conservative, I use county-class clustered standard errors as the reference case.
} 
the reduction in feed-in tariffs. The resulting (absolute) effects of the reduction in feed-in tariffs are then likely to be overestimated. The policy design, however, allows me to estimate, to a certain degree, the magnitude of self-selection and its impact on the effect of a change in feed-in tariffs on the deployment of new installations. Consistent with the simple theoretical model presented in Section 3, capacity choices of larger systems might be influenced by the introduction of the new size class.

To identify this selection effect, I would ideally observe the capacity distributions of new installations under a uniform cut in feed-in tariffs, i.e. affecting both size classes equally, as well as under feed-in tariff changes with size differentiated tariffs. While I observe the latter after the PV Amendment, the former requires an assumption about the counterfactual distribution without the change in administrative size classes. Therefore, I estimate a counterfactual distribution, using a bunching approach based on Chetty et al. (2011). The identifying assumption for inference is that the capacity distribution from one to $20 \mathrm{~kW}$ would have been smooth without the differentiation of feed-in tariffs by size classes. As shown in Figure 3, the distribution remains stable across years before the size-class change, lending credibility to this assumption. ${ }^{27}$

Chetty et al. (2011) as well as Ito and Sallee (2018) estimate the counterfactual distribution by fitting a polynomial up to a power of $q$ and including binary variables to control for excess bunching. I estimate the following equation using ordinary least squares (OLS):

$$
S_{m, y, k}=\sum_{i=0}^{q} \alpha_{i}\left(b i n_{k}\right)^{i}+\gamma D_{10}+\mu_{m, y}+\epsilon_{m, y, k},
$$

where $S_{m, y, k}$ is the share of the number of new installations within each one $\mathrm{kW}$ bin $k$ in total new installations in month $m$ and year $y .{ }^{28} \operatorname{bin}_{k}$ indicates the respective one $\mathrm{kW}$ bin of installed capacity $\left(\operatorname{bin}_{k}=\{1,2, \ldots, 20\}\right) . D_{10}$ is a binary variable that equals one for the $10 \mathrm{~kW}$ bin after the enactment of the PV Amendment. $\mu_{m, y}$ are month-year fixed effects and $\epsilon_{m, y, k}$ is the usual white-noise error term.

Following Chetty et al. (2011), I define excess bunching at the $10 \mathrm{~kW}$ bin $\left(\widehat{B}_{m, y}\right)$ as the difference between the observed share $\left(S_{m, y, 10}\right)$ and the counterfactual share $\left(\widehat{S}_{m, y, 10}-\widehat{\gamma} D_{10}\right)$ of the $10 \mathrm{~kW}$ bin. However, for the counterfactual distribution, the simple deduction of $\widehat{\gamma} D_{10}$ would violate the constraint that the area under the counterfactual distribution must be the same as under the original distribution. I adjust the dependent variable in an iterative manner such that the fitted values fulfil this "integration constraint" (Chetty et al., 2011), i.e. the sum of fitted

\footnotetext{
${ }^{27}$ I expect a change in relative deployment between the two size classes, i.e. a movement of proportions from large to small installations, as the relative stronger reduction of feed-in tariff affects larger installations to a greater extent. Consequently, I focus only on the spike at $10 \mathrm{~kW}$. Under the identifying assumption of a smooth capacity distribution in absence of the size differentiation, this spike is only driven by the design of the policy, i.e. the introduced discontinuities in the marginal feed-in tariff function.

${ }^{28} \mathrm{I}$ conduct the analysis on a national level to obtain a sufficient number of observations in each capacity bin.
} 
values equals one in each period. Therefore, I scale the shares in bins larger than $10 \mathrm{~kW}$ by the amount of excess bunching relative to the overall share of the larger size class in the respective period. The underlying assumption is that the distribution is shifted from the right. ${ }^{29}$

$$
S_{m, y, k}\left(1+\mathbb{1}[k>10] \frac{\widehat{B}_{m, y}}{\sum_{k=11}^{20} S_{m, y, k}}\right)=\sum_{i=0}^{q} \alpha_{i}\left(\operatorname{bin}_{k}\right)^{i}+\gamma D_{10}+\mu_{m, y}+\epsilon_{m, y, k}
$$

This procedure differs from the approach used by Chetty et al. (2011) due to differences in characteristics of the underlying data. Since PV system sizes are rather discrete and investors can control installation size perfectly, excess bunching appears rather to be a point mass (in contrast to the case of income as in Saez (2010) and Chetty et al. (2011)). In the empirical setting, bins with the size of one $\mathrm{kW}$ and a polynomial with degree seven $(q=7)$ yield the best fit. To enhance precision in estimating the counterfactual distribution, I exploit variation over time in addition to cross-sectional variation across capacity bins. To facilitate comparability across time periods, I use shares of new installations within each bin instead of the absolute number as in Chetty et al. (2011).

I use the estimated counterfactual distribution of capacity choices to adjust the sample of county-month-size class observations of new capacity additions for excess bunching as follows. Before the PV Amendment, the newly installed capacity of all bins remains the same. In regression analysis of changes in weights of capacity bins before and after the PV Amendment, I find that the largest impact on the distribution occurs up to the $16 \mathrm{~kW}$ bin. ${ }^{30}$ Therefore, after the PV Amendment, I adjust only monthly capacity additions in bins from $10 \mathrm{~kW}$ up to $16 \mathrm{~kW}$. For the $10 \mathrm{~kW}$ bin, I deduct the excess mass and distribute it to the bins from $11 \mathrm{~kW}$ to $16 \mathrm{~kW}$. The estimate of the excess mass at the $10 \mathrm{~kW}$ bin is the difference of the actual and estimated number of installations within this bin in each period. I calculate the latter by multiplying the total number of installations within a month and county area by the respective share of the fitted value for the $10 \mathrm{~kW}$ bin from Equation 10 after subtracting $\widehat{\gamma} D_{10} \cdot{ }^{31}$ The estimated counterfactual capacity addition within the $10 \mathrm{~kW}$ bin is the estimated counterfactual number of observations multiplied by 10 . I redistribute the estimated excess number of installations at $10 \mathrm{~kW}$ on the installation bins larger than $10 \mathrm{~kW}$ according to the share of fitted values from Equation 10. The number of additional installations is multiplied by the respective size in each bin (e.g. for the $12 \mathrm{~kW}$ bin, the number of additional installations is multiplied by 12) to translate these figures into additional newly built capacities. As a last step, I aggregate capacities in each bin to the respective size classes (up to $10 \mathrm{~kW}$ or larger than 10 up to $20 \mathrm{~kW}$ ) for each month and county.

\footnotetext{
${ }^{29} \mathrm{~A}$ visual inspection of Figure 3 and an additional statistical analysis of estimating shares of newly installed capacity in one $\mathrm{kW}$ bins, which can be found in Appendix C, support this assumption.

${ }^{30}$ The analysis can be found in Appendix C.

${ }^{31}$ As the focus is on identifying excess bunching, I consider only positive excess mass. If the excess mass is less than zero, the newly installed capacity in this region and month will remain unchanged.
} 


\section{Results}

\subsection{Effects of the Reduction in Marginal Feed-in Tariffs}

I estimate three different specifications of Equation 8 that differ with respect to the adjustments made in the dependent variable to control for excess bunching. Comparing the different estimates gives a first impression of the importance of accounting for excess bunching. Furthermore, they are key to identifying the effect of excess bunching on newly installed capacity presented in Section 6.3.

The estimated average effects of the reduction in marginal feed-in tariffs on the newly installed capacity within the larger size class are shown in Table $2 .{ }^{32}$ Since I do not observe whether installations are built under the protection clause from April to the end of June 2012, I use July 2012 instead of April 2012 as the reference case for the start of the PV Amendment, dropping all observations within the period from April to June 2012 in these specifications. This approach ensures that all newly built systems receive the feed-in tariffs valid under the PV Amendment. As a robustness check, I present the estimated effects including the period from April to July 2012 along. Consequently, I estimate three different specifications for each possible starting date of the policy change (April and July 2012). In the first specification presented in columns 1 and 4, respectively, there are no adjustments made to control for excess bunching in the $10 \mathrm{~kW}$ bin. In columns 3 and 6 , the dependent variable has been adjusted for excess bunching using the procedure outlined in Section 5.2. In the specification "Excess Mass" in column 2 and 5, the excess mass at $10 \mathrm{~kW}$ was deducted from the dependent variable in the smaller size class, but not redistributed on the larger size class.

Table 2: Summary of Marginal Effects on Capacity Additions

\begin{tabular}{l|ccc|ccc}
\hline \hline & $(1)$ & $(2)$ & $(3)$ & $(4)$ & $(5)$ & $(6)$ \\
\hline Marginal effect & $-0.569^{* * *}$ & $-0.486^{* * *}$ & $-0.279^{* * *}$ & $-0.591^{* * *}$ & $-0.511^{* * *}$ & $-0.294^{* * *}$ \\
& $(0.006)$ & $(0.007)$ & $(0.009)$ & $(0.006)$ & $(0.007)$ & $(0.009)$ \\
\hline Observations & 48,240 & 48,240 & 48,240 & 45,828 & 45,828 & 45,828 \\
Time Fixed Effects & Yes & Yes & Yes & Yes & Yes & Yes \\
County-Year Fixed Effects & Yes & Yes & Yes & Yes & Yes & Yes \\
County-Class Fixed Effects & Yes & Yes & Yes & Yes & Yes & Yes \\
Amendment start in & April & April & April & July & July & July \\
Specification & Naive & Excess Mass & Bunching & Naive & Excess Mass & Bunching \\
\hline \hline
\end{tabular}

Notes: This table shows the marginal effect of the dummy variable for the larger size class after the enactment of the PV Amendment obtained in a Poisson Pseudo-Maximum Likelihood (PPML) regression of monthly capacity additions on countyyear, county-class, size-class and month-year fixed effects as well as on monthly average end-use offer prices for electricity in the respective county. To obtain the marginal effect, the estimated coefficient $\beta$ is adjusted by $(\exp (\beta)-1)$. Standard $\operatorname{errors}$ are in parentheses and clustered at the county-class level. $* \mathrm{p}<0.10,{ }^{* *} \mathrm{p}<0.05, * * * \mathrm{p}<0.01$.

\footnotetext{
${ }^{32}$ The table shows the marginal effect of the dummy variable indicating the larger size class and the time period after the enactment of the PV Amendment. To obtain the marginal effect, I adjust the estimated coefficient $\beta$ by $(\exp (\beta)-1)$. Multiplying this marginal effect by 100 yields a relative change in per cent.
} 
The effects in all specifications are negative and statistically significant at all conventional levels of significance. In the preferred specification (column 6), the effect of the reduction in marginal feed-in tariffs is -0.294 . Hence, the monthly capacity of new installations in the larger size class within a county decreases by around 29 per cent after the enactment of the PV Amendment. ${ }^{33}$ Comparing this estimate to the one obtained when the period of the protection clause (April to June 2012) is included (column 3) suggests that neglecting the protection clause would lead to a smaller effect of a feed-in tariff of around 1.5 percentage points. This finding is consistent with installations from April to June 2012 being in the larger size class and still benefiting from the higher feed-in tariff under the protection clause.

Comparing the effects with ("Bunching" specification) and without bunching adjustments ("Naive" specification) reveals the potential bias, if excess bunching at $10 \mathrm{~kW}$ is not taken into account. The difference in effects between both models is striking, with estimated effects in the bunching adjusted model being considerably smaller, i.e. about half the size.

\subsection{Robustness Checks}

I investigate the robustness of the results with respect to several dimensions. First, comparing new capacity additions in the larger to those in the smaller size class is only indicative, if the trend in capacity additions were the same in the absence of the change in size classes. Otherwise, differential trends may also be captured by the binary variable of the size class change. One example could be different anticipation effects of feed-in tariff changes in both size classes. This difference would bias the estimated effect of the reduction in feed-in tariffs on the deployment of new capacity of larger installation sizes. The parallel trend assumption is not testable, but I investigate the development of trends in the period before the PV Amendment. I include additional interactions of the size class dummy variable with time dummy variables. The coefficients of the interaction terms are shown in Figure 5 and are statistically insignificant before the PV Amendment, supporting the claim that both size classes exhibit the same pre-trends in monthly capacity additions.

Second, solar PV installations may receive subsidies in addition to feed-in tariffs. Other subsidy programmes for solar PV could potentially interfere with the presented design, if they would impact both size classes differently at the time of the PV Amendment. Using the database of BINE (2015), I check manually whether there are subsidy programmes from local utilities, federal state governments, or other (public) agencies that fulfil these criteria. Although there are other financing opportunities, I found no subsidy programs that either differentiate across size classes or change

\footnotetext{
${ }^{33}$ The outlined procedure to adjust for excess bunching is likely to introduce measurement error in the dependent variable. I adjust new capacity additions to bunching based on estimated parameters. Therefore, errors may result from potential misspecification in the excess bunching estimation and because those estimated parameters are not fixed, but random variables. While this measurement error adds noise to the dependent variable, it does not bias the coefficient estimates but increases standard errors (Best and Kleven, 2018). Consistently, the specifications with bunching adjustment display the largest standard errors in Table 2.
} 
this differentiation around the time of the PV Amendment. Therefore, the influences of other subsidies should be captured by the time and county-size-class fixed-effects. ${ }^{34}$

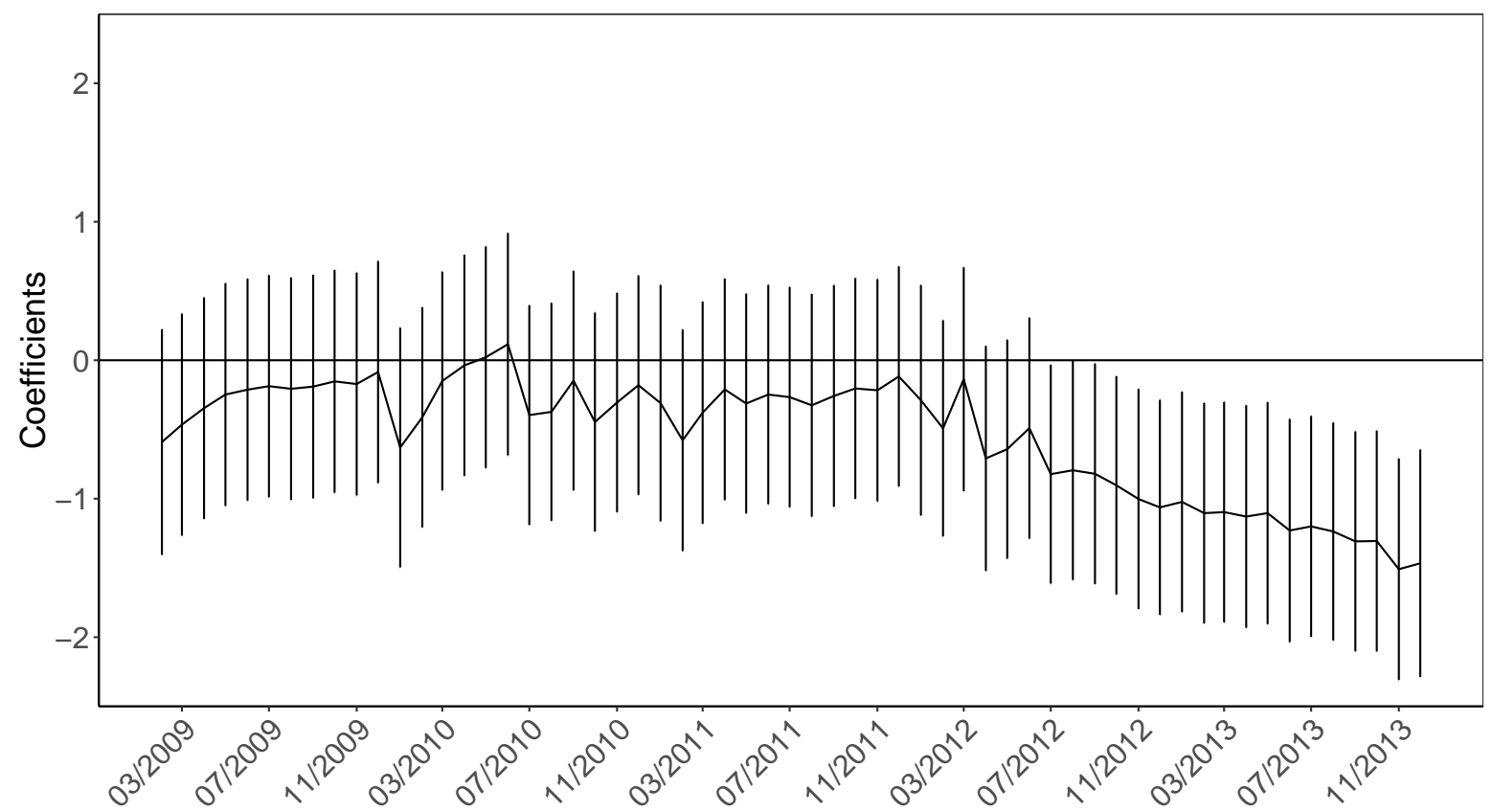

Figure 5: Differences in Trends in Capacity Additions across Size Classes

Notes: The solid line depicts estimates for the interaction of the respective time period and a dummy variable for the larger size class. The vertical lines show the 95 percent confidence interval for the coefficient estimate.

Third, conducting the analysis on a monthly level from January 2009 to December 2013 leaves me with a long time series of 60 periods. Serial correlation may bias the standard errors of the estimates downwards (Bertrand et al., 2004). Although I allow for correlation within countysize-class clusters in my main specification and, as a robustness check, within counties as well, I collapse months before and after the PV Amendment to compare pre- and post deployment for a more conservative estimate as suggested by Bertrand et al. (2004). The effects are still statistically significant at any conventional level and of slightly larger magnitude (-0.32 for April 2012 and -0.33 for July 2012, respectively).

Fourth, instead of the bunching adjustment I re-estimate the model with an "Intent-to-treat" strategy similar to a robustness check used by Best and Kleven (2018). I aggregate capacity of PV

\footnotetext{
${ }^{34}$ The propensity to take up these subsidies could potentially be increasing in installation size. However, I do not have information on the subsidy uptake behaviour. Therefore, I cannot check whether this might be the case. Nevertheless, the time constant part of this effect would be captured by the fixed effects for the larger size class. Furthermore, this database might not cover all special promotion offers by actors on a deeper local level, such as individual craftsmen in municipalities. To the extent that these offers are missing, I cannot check whether there are differentiated subsidies or special offers at the local level.
} 
systems only up to nine $\mathrm{kW}$ as well as from larger than nine to $20 \mathrm{~kW}$. This approach includes installations at $10 \mathrm{~kW}$ in the larger size class and thereby controls for potential self-selection into the smaller size class in response to the introduction of the new size classes. However, this strategy does not account for the reduction in capacity that occurred because those systems would have been built larger without the size class change. Therefore, it is not surprising that I find negative, statistically significant effects of a slightly greater magnitude (-0.33 for April 2012 and -0.35 for July 2012) than in the "Bunching" specification (-0.28 and -0.29 in columns 3 and 6 in Table 2, respectively).

Fifth, I focus on capacity additions since this measure captures the average size of new PV systems (which is important in this paper) as well as the number of new installations. However, investigating only the number of new installations as the dependent variable instead of new capacity additions in the empirical model specified in Equation 8 reveals an effect of similar magnitude in relative terms as for the "Bunching" model. Estimating the effect on the number of installed PV systems yield reductions of around 28 per cent for April 2012 and of 29 per cent for July 2012, respectively.

Table 3: Intent-to-treat Strategy: Multiple Size Classes

\begin{tabular}{l|cc|cc}
\hline \hline Dependent variable & \multicolumn{2}{|c|}{ Capacity } & \multicolumn{2}{c}{ Number of installations } \\
Amendment enacted in & April 2012 & July 2012 & April 2012 & July 2012 \\
& $(1)$ & $(2)$ & $(3)$ & $(4)$ \\
\hline Size class >9-20 kW & $-33 \%$ & $-35 \%$ & $-28 \%$ & $-29 \%$ \\
Size class > $20-29 \mathrm{~kW}$ & $-65 \%$ & $-68 \%$ & $-64 \%$ & $-68 \%$ \\
Size class > $29-39 \mathrm{~kW}$ & $-70 \%$ & $-74 \%$ & $-70 \%$ & $-74 \%$ \\
Size class > 39-50 kW & $-60 \%$ & $-67 \%$ & $-59 \%$ & $-66 \%$ \\
Size class >50-60 kW & $-62 \%$ & $-69 \%$ & $-63 \%$ & $-70 \%$ \\
$\ldots$ & & & & \\
Size class >90-99 kW & $-51 \%$ & $-64 \%$ & $-50 \%$ & $-64 \%$ \\
\hline \hline
\end{tabular}

Notes: This table shows the marginal effects of the binary variables for the respective size classes after the enactment of the PV Amendment obtained in a Poisson Pseudo-Maximum Likelihood (PPML) regression of monthly capacity additions on county-year, county-class, size-class and month-year fixed effects as well as on monthly average end-use offer prices for electricity in the respective county. All marginal effects are statistically significant at all conventional levels, with standard errors being clustered at the county-size-class level in all four regressions.

Sixth, even though residential scale systems are mainly up to $20 \mathrm{~kW}$, there could be concerns about the censoring of the data, especially given that the smallest size-class before the PV Amendment encompassed new installations up to $30 \mathrm{~kW}$ and the new size classes after the amendment are up to $10 \mathrm{~kW}$ and from larger than 10 to $40 \mathrm{~kW}$. Extending the framework to incorporating system sizes up to $40 \mathrm{~kW}$ (or even larger up to $100 \mathrm{~kW}$ ), however, is associated with some issues. There are, for example, additional changes in the discontinuities of the marginal feed-in tariff function along different system sizes. Before the enactment of the PV Amendment, $30 \mathrm{~kW}$ was 
a popular system size (especially for farmers) as it was just at the border of the size class. With the enactment of the PV Amendment, this border was moved to $40 \mathrm{~kW}$. In addition to that, the mass of individual solar PV installations is concentrated on smaller installations sizes as around 70 per cent of all installations are of a size of up to $20 \mathrm{~kW}$. This impedes the estimation of a counterfactual distribution for larger system sizes given the lack of observations in some areas of the distribution. Furthermore, larger installation sizes feature different characteristics (which may influence installation costs) and are erected by different investor types. These issues may threaten identification, when I extend the analysis to more size classes. Nevertheless, as a robustness check, I present the results of estimating Equation 8 with additional size classes. To this purpose, I augment the empirical model with additional binary variables indicating the other size classes after the PV Amendment. As outlined above, the application of the bunching adjustment approach in such a setting is not trivial. Instead, I make use of the "Intent-to-treat" strategy discussed above and extend it to the other size classes. I aggregate installed capacity within each county and month in the following size classes: up to nine $\mathrm{kW}$, larger than nine up to $20 \mathrm{~kW}$, larger than 20 up to $29 \mathrm{~kW}$, larger than 29 up to $39 \mathrm{~kW}$, larger than 39 up to $50 \mathrm{~kW}$, larger than 50 up to $60 \mathrm{~kW}$, larger than 60 up to $70 \mathrm{~kW}$, larger than 70 up to $80 \mathrm{~kW}$, larger than 80 up to $90 \mathrm{~kW}$, and larger than 90 up to $99 \mathrm{~kW}$. These size classes are chosen such that size class changes at 10, 30, 40 and $100 \mathrm{~kW}$ are incorporated.

Table 3 summarizes the results for the marginal effects of different size classes for the dependent variable being new capacity additions (in column 1 and 2) and the number of new installations (column 3 and 4). As in Table 2 the model has been estimated with (column 1 and 3) and without the observations during the period from April to July 2012 (column 2 and 4). While there are negative marginal effects for all size classes, these marginal effects in absolute values do not monotonically increase with size classes, although the differences in feed-in tariffs are amplified with increasing capacity size. In particular, the large absolute effect in the larger than 29 up to $39 \mathrm{~kW}$ size class is unexpected ex-ante, as this size class benefits relative to other size classes and especially relative to the size class from larger than 39 to $50 \mathrm{~kW}$ which is also affected by a re-evaluation of size classes within the PV Amendment (and an associated decrease in the level of the feed-in tariff). However, substantial heterogeneity in types of systems and installation cost makes it hard to compare size classes and interpret the results.

Seventh, in addition to the estimation of effects averaged over time, I investigate how these effects evolve over time after the enactment of the PV Amendment. Instead of a single binary variable, I include interactions of the size-class binary variable with the time period binary variables after the PV Amendment. Figure 6 shows the estimated marginal effects of these interaction terms along with the respective 99 per cent confidence interval. With the exception of June 2012, all marginal effects are negative and statistically significant. Until the beginning of 2013, the effects remain in the same range, with a steady downward trend in 2013. The statistically insignificant effect in June 2012 and the "jump" in the effect in this month could potentially reflect the expiration 
of the protection clause. This may suggest that a substantial amount of deployment within the larger class in the months from April to June 2012 still had the possibility to profit from the higher feed-in tariffs valid before the PV Amendment as these systems had to be commissioned by July $2012.3^{35}$

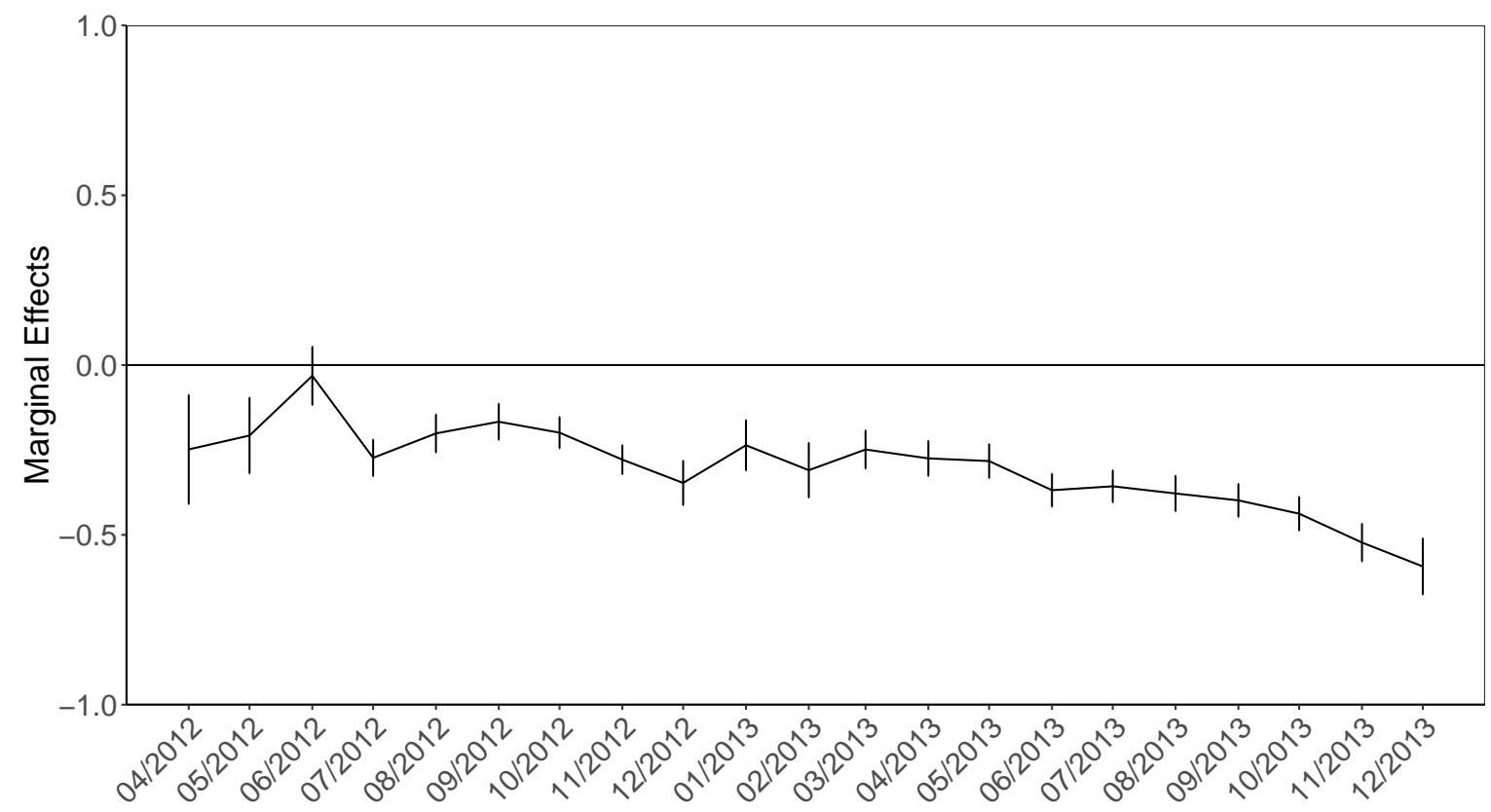

Figure 6: Dynamic Effects

Notes: The solid line depicts the marginal effects for the interaction of the respective time period and a dummy variable for the larger size class. The vertical lines show the 99 per cent confidence interval for the coefficient estimate.

\subsection{Additional Effects from Excess Bunching}

The PV Amendment contains a re-evaluation of size classes in the feed-in tariff system that leads to a steeper reduction of the marginal feed-in tariff for larger installations compared to smaller ones. This change has two implications. First, it reduces the profitability of PV systems in the larger size class, resulting in a decrease of newly installed capacity corresponding approximately to a uniform reduction in the feed-in tariff. Section 6.1 presents estimates on this channel, while controlling for excess bunching. Second, there is the impact of size-based regulation on the deployment of PV systems, i.e. installation sizes within the smaller size class become relatively more attractive compared to larger ones. This changes the capacity distribution of installations, which implies both an increase in capacity additions of smaller installations and a decrease in newly installed capacity in the larger size class. Both changes affect the estimated effects in the previous section in the

\footnotetext{
${ }^{35}$ And this may suggest that there has been a rush to install those systems up to the last moment before the expiration of the protection clause.
} 
same direction, namely a larger difference in the deployment of new PV systems between the larger and smaller size class, as evident from the large difference between the estimates recovered in the "Naive" versus the "Bunching" model. However, the overall additional effect of excess bunching on deployment of residential-scale PV systems, i.e. weighting the positive effect on more installed capacity in the smaller size class against the negative effect on the larger size class, is not identified by the difference in estimates of the "Naive" and the "Bunching" model. This difference is subject to double counting of potentially the same installations switching from the larger (negative effect on deployment within the larger size class) to the smaller size class (positive effect on smaller size classes) around the size class border. However, since both effects do not cancel out as they are asymmetric due to different installation sizes, excess bunching might have an additional effect on the deployment of residential scale solar PV systems.

To identify and quantify this effect, I use the estimates from the three different specifications ("Naive", "Excess Mass", and "Bunching"). The effect of the reduction in feed-in tariffs of five per cent, while controlling for excess bunching, equals the effect in the "Bunching" specification $\left(\delta_{\text {bunching }}=-0.294\right) \cdot{ }^{36}$ The positive effect on smaller installations can be identified by the difference in effects between the "Excess Mass" and the "Naive" specification $\left(\delta_{\text {excess }}-\delta_{\text {naive }}=\right.$ $(-0.511)-(-0.591)=0.080)$. This number represents the differences in effects with and without the deduction of the excess mass, which equals the positive deployment effect of the smaller size class. The negative effect on capacity deployment in the larger size class can be disentangled by the effect of the redistribution of excess mass, given by the difference in effects between the "Excess Mass" and "Bunching" specification $\left(\delta_{\text {excess }}-\delta_{\text {bunching }}=(-0.511)-(-0.294)=-0.217\right)$.

The overall effect of the excess bunching on overall deployment is the sum of the positive and negative effect:

$$
\begin{aligned}
\widehat{\delta}_{\text {net }} & =\left(\widehat{\delta}_{\text {excess }}-\widehat{\delta}_{\text {naive }}\right)+\left(\widehat{\delta}_{\text {excess }}-\widehat{\delta}_{\text {bunching }}\right) \\
& =0.080+(-0.217) \\
& =-0.137
\end{aligned}
$$

The positive effect on deployment of the small class amounts to eight per cent and the negative effect on the larger size class amounts to approximately 22 per cent. Excess bunching leads to a lower overall deployment by around 14 per cent (in relation to the deployment in the larger size class). Therefore, the introduction of the new size class leads to additional lower deployment due to the incentive to build smaller installations around the border of the size class. Translating the relative decrease into absolute numbers, I use the average capacity additions of installations from 10 up to $20 \mathrm{~kW}$ before the PV Amendment, which is around $159 \mathrm{~kW}$ on a county-month level as can be seen from Table 1. Multiplying this value by 402 (the number of counties in Germany) and 12 (the number of months per year), results in about $767 \mathrm{MW}$ on a national level per year. The

\footnotetext{
${ }^{36}$ In the following, $\delta$ denotes the respective marginal effect estimated by Equation 8, i.e. $\delta=\exp (\beta)-1$.
} 
total reduction in deployment induced by the excess bunching amounts to around 105 MW (13.7 percent of $767 \mathrm{MW}$ ) per year.

Furthermore, the bunching effect not only lowers overall deployment but it also leads to installation of systems that are on average more expensive in terms of the average feed-in tariff per $\mathrm{kW}$. I calculate the hypothetical cost to compensate for this decrease in capacity additions with additional installations in the smaller size class. A back-of-the-envelope calculation for this additional annual cost is as follows:

$$
\begin{aligned}
\text { Additional Annual Cost } & =\widehat{\delta}_{n e t} * \bar{K}_{r=1, m y \leq 04 / 12} * \bar{H} * \Delta_{F I T} \\
& =13.7 \% * 767 \mathrm{MW} / \mathrm{a} * 936 \mathrm{~h} * 2.3 \mathrm{Euro} / \mathrm{MWh} \\
& =226,214 \text { Euro/a }
\end{aligned}
$$

where $\widehat{\delta}_{\text {net }}$ is the effect of excess bunching on the larger size class (13.7 per cent), $\bar{K}_{r=1, m y \leq 04 / 12}$ is the average annual capacity addition in the larger size class before April 2012 aggregated on the national level (around $767 \mathrm{MW}$ per year), $\bar{H}$ is the average irradiation in $\mathrm{kWh}$ per $\mathrm{kW}$ for installed solar PV in Germany (936 kWh/kW according to IEA (2014)), and the weighted average difference in feed-in tariffs across installation sizes (2.30 Euro per MWh). I construct the last term as the difference between the average feed-in tariff of new installations up to $10 \mathrm{~kW}$ and the average feed-in tariff of installations that would have been installed in the absence of the size class change. The latter depends on the counterfactual distribution of system sizes without the change in size classes. Since this distribution is unobservable, I use once again the share of fitted values obtained in the bunching estimation instead.

Using these assumptions, the additional annual cost amounts to around 230 thousand Euro within one year. This cost is incurred for every annual cohort of new installations that would have been installed in the larger size class without this size differentiation. Consequently, assuming no further changes in regulation, the total annual additional cost would increase for 20 years as feed-in tariffs are guaranteed for this period and would remain constant thereafter. After 19 years, the total additional cost would amount to around 4.5 million Euro (4,524,280 Euro) per year.

This cost is underestimated if (part of) the bunching is also explained by another change in the PV Amendment as discussed in Section 2.1, namely the 90 per cent compensation limit for systems larger than $10 \mathrm{~kW}$ from January 2014 on. As this change would increase the difference in average feed-in tariffs between both groups from 2.3 to 21.6 Euro per MWh, the additional cost is higher, amounting to around 2.1 million Euro per year (2,123,445 Euro). Accumulating this cost for each new cohort of installations over 20 years leads to an amount of 42.5 million Euro (42,468,900 Euro) per year. These back-of-the-envelope numbers, however, should be regarded as an upper bound. Since self-consumption is an economically attractive option, the extent to which this change in the PV Amendment contributes to the excess bunching observed in the data is unclear. 


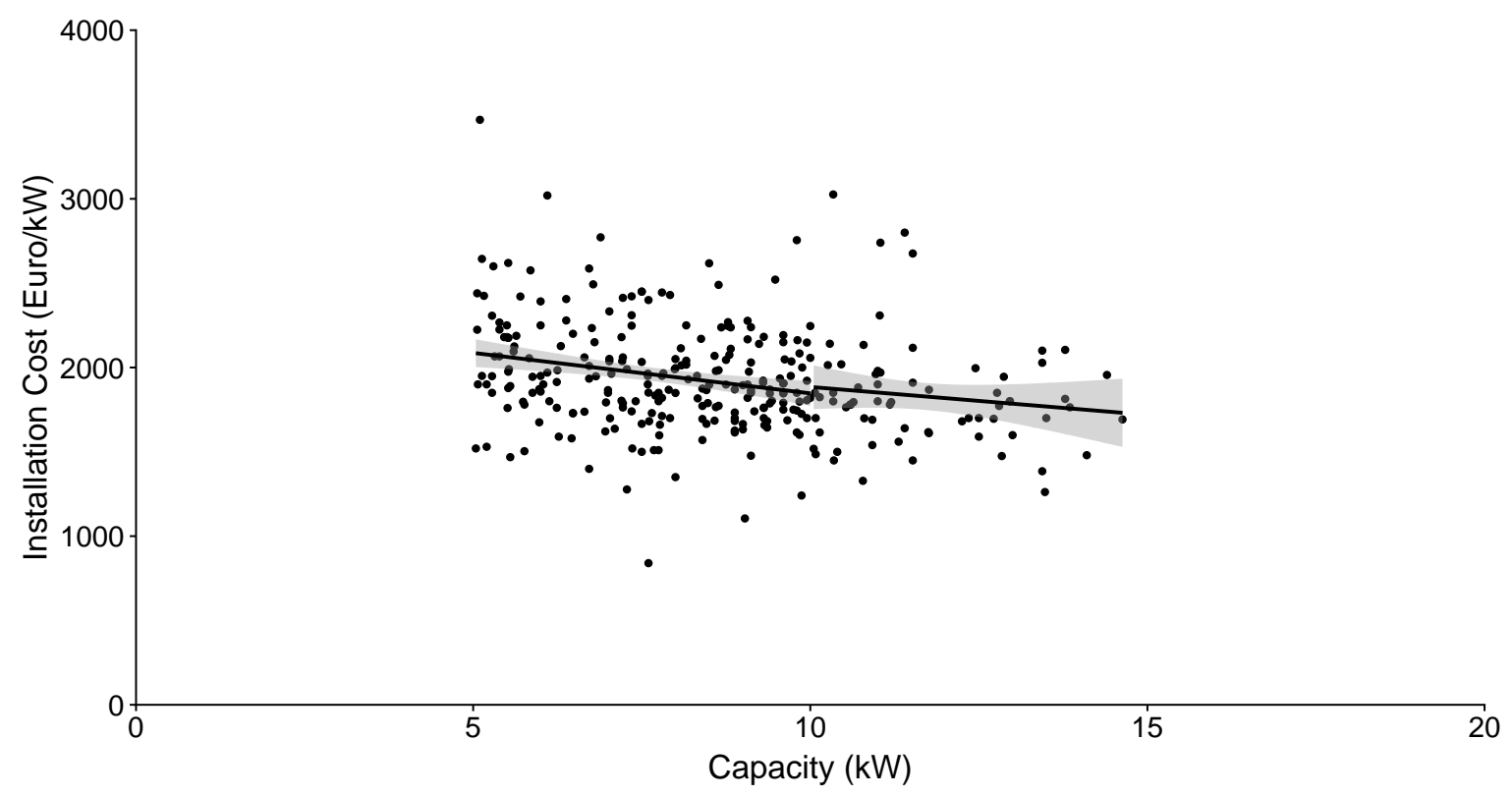

Figure 7: Differences in Specific Cost: Small vs. Larger Installations

Notes: This plot depicts the relationship between specific installation cost, i.e. Euro per kW, and the nominal capacity of solar PV systems. The dots represent installation offers (price and capacity) for solar PV systems from five to $15 \mathrm{~kW}$ posted online at photovoltaikforum.com within the period from March to May 2012. The solid lines are a linear trend for the relationship between installation cost and capacity estimated separately for offers with capacity from five up to $10 \mathrm{~kW}$ and more than 10 up to $15 \mathrm{~kW}$. The grey area depicts 95 per cent confidence intervals.

To put these numbers into context, I calculate the average annual total support cost of newly installed capacity in the size class up to $10 \mathrm{~kW}$ after the PV Amendment. Using a similar approach as for the additional cost, support cost is around 103 million Euro per year $\left(102,696,984\right.$ Euro). ${ }^{37}$ The potential annual additional cost in relation to the annual total support cost of new capacity additions in the smaller size class is around 0.2 per cent in the first year and around 4.4 per cent after 19 years. If excess bunching is driven by the 90 per cent limit, an upper bound for the relative annual additional cost ranges from around 2.1 per cent in the first year to around 41.4 per cent after 19 years.

To what extent is the additional support cost related to efficiency losses introduced by the design of the size-based regulation? To answer this question, differences in specific installation costs are a crucial determinant. Using data of installation offers in photovoltaikforum.com, a German online forum where customers can post the offers they have received, Figure 7 displays the specific installation cost, i.e. Euro per $\mathrm{kW}$, for different system sizes in the range of five to

\footnotetext{
${ }^{37}$ Additional assumptions for this calculation are average annual capacity additions for installations up to $10 \mathrm{~kW}$ before April 2012 aggregated on a national level of around $657 \mathrm{MW}$ and the average feed-in tariff for the smaller size class between April 2012 and December 2013 of 167 Euro per MWh. The latter assumes implicitly an equal distribution of deployment over time. The average feed-in tariff weighted by actual monthly deployment from April 2012 to December 2013 is 169 Euro per MWh, yielding slightly higher total annual cost.
} 
$15 \mathrm{~kW}$. The specific installation costs appear to be similar at the size class border of $10 \mathrm{~kW}$, even though specific costs in general seem to decline with increasing individual capacity. This trend would mean that smaller installations are not only more expensive in terms of support cost but also in specific installation cost. Under the assumption that the smaller systems are built because the higher feed-in tariff covers these potential additional installation cost, the amount of additional support cost can be considered to be at the upper bound of potential efficiency losses introduced by the design of the size-based regulation.

\section{Conclusion}

In this paper, I explore effects of size-based differentiation of feed-in tariffs on the deployment of residential scale solar PV systems, using variation from a change of administrative size classes within the PV Amendment 2012 of the German Renewable Energy Sources Act. I find that the reduction in marginal feed-in tariffs for larger scale residential PV systems leads to a decline in newly installed PV capacity by around 29 per cent. This effect seems large relative to the five per cent decrease in marginal feed-in tariffs, which translates into into around two per cent smaller total revenues from the PV system. However, the return on investment of the PV system is reduced by (at least) this amount. Before the PV Amendment, solar PV installations in Germany yielded a total return on investment of around eight to 12 per cent (Andor et al., 2015). Consequently, the PV Amendment reduces this return by around 20 per cent up to almost 30 per cent. This strong response to changes in revenues is also in line with evidence on discount rates of solar PV projects by De Groote and Verboven (2018). The authors find that households in Belgium use an implicit real interest rate for evaluating future benefits of solar PV systems (around 15 per cent) that is substantially higher than the real market interest rate (around 3 per cent) in their time period under study. Hence, this research supports the finding of this paper that households are highly sensitive to changes in feed-in tariffs.

Furthermore, I find that the introduction of size-based regulation provides incentives for excess bunching of new systems at the border of the smaller size class. This leads to an additional decrease in newly installed solar PV capacity in the larger size class of around 14 per cent. A back-of-theenvelope calculation suggests that excess bunching raises additional annual support cost within a range of 0.2 up to 4.4 per cent of annual support cost of new installations in the smaller size class. Since systems at the border of administrative size classes have comparable specific installation cost and the feed-in tariffs should cover these cost for systems that were built, the amount of additional support cost can be considered to be at the upper bound of the economic size of efficiency losses incurred due to the tariff design.

Ito and Sallee (2018) state that "the key cost of an ABR [attribute-based regulation] is that it creates an implicit incentive for market participants to manipulate the secondary attribute". In the case of differentiated feed-in tariffs for solar PV, this secondary attribute is the PV system 
size. ${ }^{38}$ Ito and Sallee argue in the context of fuel efficiency standards for cars that attributebased regulation could help to equalize marginal compliance cost across market participants, if each product has to comply with the standard and in absence of compliance trading. For sizedifferentiated tariffs of solar PV systems, these conditions, however, are hard to sustain because the main existing political targets apply to all eligible renewable energy technologies. ${ }^{39}$ These targets can be achieved in a flexible manner, attenuating the need to target equalization of marginal compliance (installation) cost across system sizes by the feed-in tariff regulation.

Furthermore, Ito and Sallee (2018) indicate that distributional concerns or the achievement of other (political) goals are often important reasons to implement attribute-based policies. In this case, the incurred efficiency loss equals the cost of achieving these goals (Ito and Sallee, 2018). For solar PV, size-differentiation may also reflect other political goals not mentioned in the Renewable Energy Sources Act, for example increasing participation of households in electricity generation. If these goals are to be achieved, a continuous function of the marginal feed-in tariff dependent on installation size could improve the current design with administratively determined size classes. This change would reflect differences across installation sizes but would avoid excess bunching at the size class border and its induced additional cost.

The current analysis focuses only on additional support cost and neglects other cost factors that could potentially be affected by the policy (such as curtailment cost due to grid constraints etc.). For example, size-differentiation of tariffs may also have an indirect effect on the distribution of systems across locations due to regional variation in existing building structures. The balancing of (local) electricity grids may therefore be affected. It is not clear ex-ante though whether this effect on electricity grids is a net benefit or adds to the cost. Even if it were a net benefit the question is whether it exceeds the efficiency gains from targeting the locational imbalances of demand and supply directly, for example by strengthening regional price signals as proposed by Löschel et al. (2013). These issues, however, are beyond the scope of this paper and are left for future research.

Size-based and, in general, attribute-based regulation is widespread in practice, even within renewable support schemes. Investigation of the effects of size-differentiated feed-in tariffs is and remains important. This holds also for Germany with the recent transition to auctions for determining feed-in tariff (feed-in premium) levels since auctioning is only mandatory for large installations. ${ }^{40}$ Not only do size-differentiated feed-in tariffs remain in place, but size-differentiation itself is likely to be an important aspect in the regulation for renewable energy technologies in the future.

\footnotetext{
${ }^{38}$ The main characteristic targeted by the regulation of feed-in tariffs is electricity generated by renewable energy technologies.

${ }^{39}$ There are even sub-goals for solar PV systems but these are not differentiated by system sizes.

${ }^{40}$ For example, the size threshold for solar PV is $750 \mathrm{~kW}$.
} 


\section{References}

Alizamir, S., de Vericourt, F., Sun, P., 2016. Efficient Feed-In Tariff Policies for Renewable Energy Technologies. Operations Research 61, 52-66.

Anderson, S.T., Sallee, J.M., 2011. Using Loopholes to Reveal the Marginal Cost of Regulation: The Case of Fuel-Economy Standards. American Economic Review 101, 1375-1409.

Andor, M., Frondel, M., Vance, C., 2015. Installing Photovoltaics in Germany: A License to print Money? Economic Analysis and Policy 48, 106-116.

Balta-Ozkan, N., Yildirim, J., Connor, P.M., 2015. Regional Distribution of Photovoltaic Deployment in the UK and its Determinants: A Spatial Econometric Approach. Energy Economics 51, 417-429.

Benedetti, L., 2014. Developing a Comprehensive Renewable Cost Data Collection Process to Support Italian Policy Makers. Gestore Servizi Energetici (GSE).

Bertrand, M., Duflo, E., Mullainathan, S., 2004. How Much Should We Trust Differences-in-Differences Estimates? Quarterly Journal of Economics 119, 249-275.

Best, M.C., Kleven, H.J., 2018. Housing Market Responses to Transaction Taxes: Evidence from Notches and Stimulus in the U.K. Review of Economic Studies 85, 157-193.

BINE, 2015. Förderung Erneuerbare Energien und Energieeinsparung. http://www.energiefoerderung.info, retrieved in Spring 2015. BINE Informationsdienst.

BNetzA, 2016. Feed-In Tariffs for Solar PV ("Degressions- und Vergütungssätze"). accessed: 21.06.2016. German Federal Network Agency.

BNetzA-BKartA, 2013. Monitoringbericht 2013. Monitoringbericht gemäß $\S 63$ Abs. 3 i. V. m. $\S 35$ EnWG und $\S$ 48 Abs. 3 i. V. m. $\S 53$ Abs. 3 GWB, Stand: Dezember 2013. Bundesnetzagentur (Federal Network Agency) and Bundeskartellamt (Federal Competition Authority).

Borenstein, S., 2017. Private Net Benefits of Residential Solar PV: The Role of Electricity Tariffs, Tax Incentives, and Rebates. Journal of the Association of Environmental and Resource Economists 4, S85-S122.

Bushnell, J., Wolfram, C., 2012. Enforcement of Vintage Differentiated Regulations: The Case of New Source Review. Journal of Environmental Economics and Management 64, 137-152.

Cameron, A.C., Trivedi, P.K., 2013. Regression Analysis of Count Data. Second Edition. Cambridge University Press.

Carley, S., Baldwin, E., MacLean, L.M., Brass, J.N., 2017. Global Expansion of Renewable Energy Generation: An Analysis of Policy Instruments. Environmental and Resource Economics 68, 397-440.

Chetty, R., Friedman, J., Olsen, T., Pistaferri, L., 2011. Adjustment Costs, Firm Responses, and Micro vs. Macro Labor Supply Elasticities: Evidence from Danish Tax Records. Quarterly Journal of Economics 126, 327-354.

Crago, C.L., Chernyakhovskiy, I., 2017. Are Policy Incentives for Solar Power Effective? Evidence from Residential Installations in the Northeast. Journal of Environmental Economics and Management 81, 132-151.

De Groote, O., Pepermans, G., Verboven, F., 2016. Heterogeneity in the Adoption of Photovoltaic Systems in Flanders. Energy Economics 59, 45-57.

De Groote, O., Verboven, F., 2018. Subsidies and Time Discounting in New Technology Adoption: Evidence from Solar Photovoltaic Systems. Working Paper.

ene't, 2014. Final Consumer Tariffs Electricity ("Endkundentarife Strom"). ene't GmbH.

Eurostat, 2018. Electricity prices for household consumers - bi-annual data (from 2007 onwards) [nrg_pc_204]. accessed: 30.08 .2018 .

Feger, F., Pavanini, N., Radulescu, D., 2017. Welfare and Redistribution in Residential Electricity Markets with Solar Power. Working Paper.

Geroski, P.A., 2000. Models of Technology Diffusion. Research Policy 29, 603-625.

Gillingham, K., Bollinger, B., 2012. Peer Effects in the Diffusion of Solar Photovoltaic Panels. Marketing Science $31,900-912$. 
Gillingham, K., Deng, H., Wiser, R., Darghouth, N., Nemet, G., Barbose, G., Rai, V., Dong, C., 2016. Deconstructing Solar Photovoltaic Pricing: The Role of Market Structure, Technology, and Policy. Energy Journal 37, $231-250$.

Götzke, F., Rave, T., 2016. Exploring Heterogeneous Growth of Wind Energy across Germany. Utilities Policy 41, 193-205.

Grau, T., 2014. Responsive Feed-in Tariff Adjustment to Dynamic Technology Development. Energy Economics 44, $36-46$.

Gray, W.B., Shadbegian, R.J., 2003. Plant Vintage, Technology, and Environmental Regulation. Journal of Environmental Economics and Management 46, 384-402.

Graziano, M., Gillingham, K., 2014. Spatial Patterns of Solar Photovoltaic System Adoption: The Influence of Neighbors and the Built Environment. Journal of Economic Geography 15, 815-839.

Gruenspecht, H.K., 1982. Differentiated Regulation: The Case of Auto Emissions Standards. American Economic Review 72, 328-331.

Hughes, J.E., Podolefsky, M., 2015. Getting Green with Solar Subsidies: Evidence from the California Solar Initiative. Journal of the Association of Environmental and Resource Economists 2, 235-275.

IE Leipzig, 2011. Vorbereitung und Begleitung der Erstellung des Erfahrungsberichts gemäß § 65 EEG - Vorhaben IIc Solare Strahlungsenergie. Endbericht. Leipziger Institut für Energie GmbH.

IEA, 2014. Trends 2014 in Photovoltaic Applications. Survey Report of Selected IEA Countries between 1992 and 2013. Report IEA-PVPS T1-25:2014.

IEA, 2017. Trends 2017 in Photovoltaic Applications. Survey Report of Selected IEA Countries between 1992 and 2016. Report IEA PVPS T1-32:2017.

Ito, K., Sallee, J.M., 2018. The Economics of Attribute-Based Regulation: Theory and Evidence from Fuel Economy Standards. Review of Economics and Statistics 100, 319-336.

Jaffe, A.B., Newell, R.G., Stavins, R.N., 2003. Technological Change and the Environment. Elsevier Science B.V.. chapter Handbook of Environmental Economics, Volume 1. pp. 461-516.

Jaffe, A.B., Newell, R.G., Stavins, R.N., 2005. A Tale of Two Market Failures: Technology and Environmental Policy. Ecological Economics 54, 164-174.

Kirkpatrick, A.J., Bennear, L.S., 2014. Promoting Clean Energy Investment: An Empirical Analysis of Property Assessed Clean Energy. Journal of Environmental Economics and Management 68, 357-375.

Klier, T., Linn, J., 2016. The Effect of Vehicle Fuel Economy Standards on Technology Adoption. Journal of Public Economics 133, 41-63.

Lamp, S., 2015. The Impact of Short-Lived Weather Outliers on Household Investment. Working paper; http: //papers.ssrn.com/sol3/papers.cfm?abstract_id=2463570.

Leepa, C., Unfried, M., 2013. Effects of a Cut-Off in Feed-In Tariffs on Photovoltaic Capacity: Evidence from Germany. Energy Policy 56, 536 - 542.

Lehmann, P., Söderholm, P., 2018. Can Technology-Specific Deployment Policies be Cost-Effective? The Case of Renewable Energy Support Schemes. Environmental and Resource Economics 71, 575-505.

Löschel, A., Flues, F., Pothen, F., Massier, P., 2013. Den Strommarkt an die Wirklichkeit anpassen: Skizze einer neuen Marktordnung. ZEW Discussion Paper No. 13-065 .

Meng, K., 2017. Using a Free Permit Rule to Forecast the Marginal Abatement Cost of Proposed Climate Policy. American Economic Review 107, 748-784.

Nelson, R.A., Tietenberg, T., Donihue, M.R., 1993. Differential Environmental Regulation: Effects on Electric Utility Capital Turnover and Emissions. Review of Economics and Statistics 75, 368-373.

Ossenbrink, J., 2017. How Feed-In Remuneration Design Shapes Residential PV Prosumer Paradigms. Energy Policy 108, 239-255.

Requate, T., 2015. Green Tradable Certificates versus Feed-In Tariffs in the Promotion of Renewable Energy Shares. Environmental Economics and Policy Studies 17, 211-239. 
Rode, J., Weber, A., 2016. Does Localized Imitation Drive Technology Adoption? A Case Study on Rooftop Photovoltaic Systems in Germany. Journal of Environmental Economics and Management 78, 38-48.

Saez, E., 2010. Do Taxpayers Bunch at Kink Points? American Economic Journal: Economic Policy 2, 180-212. Santos Silva, J.M.C., Tenreyro, S., 2006. The Log of Gravity. Review of Economics and Statistics 88, 641-658.

Smith, M.G., Urpelainen, S., 2014. The Effect of Feed-in Tariffs on Renewable Electricity Generation: An Instrumental Variables Approach. Environmental and Resource Economics 57, 367-392.

Stavins, R.N., 2006. Vintage-Differentiated Environmental Regulation. Stanford Environmental Law Journal 25:29, 29-63.

Tietenberg, T., 1978. Spatially Differentiated Air Pollutant Emission Charges: An Economic and Legal Analysis. Land Economics 54, 265-277.

ÜNB, 2014. Renewable Energy Installations Register ("EEG Anlagestammdaten"). TSO - 50Hertz Transmission GmbH, Amprion GmbH, TransnetBW GmbH and Tennet TSO GmbH.

ZSW, 2014. Vorbereitung und Begleitung der Erstellung des Erfahrungsberichts 2014 gemäß§ 65 EEG - Vorhaben IIc Solare Strahlungsenergie. Zentrum für Sonnenenergie- und Wasserstoff-Forschung. 


\section{Appendix A Theoretical Model - Extension to Self-consumption}

During the time period in this paper, self-consumption becomes economically favourable since the feed-in tariff drops below most residential end-use prices for electricity. This extends the revenue possibilities for a PV system. Under this regime the expression of the expected discounted revenue changes to $\sum_{t=1}^{T} \beta_{i}^{t}\left(\alpha_{i} k_{i} \times p_{i}+\left(1-\alpha_{i}\right) k_{i} \times F I T\left(k_{i}\right)\right) \times H_{i}$, where $\alpha_{i}$ is the (individual) share of electricity generated by the PV system that can be self-consumed, and $p_{i}$ is the (expected) residential electricity price. ${ }^{41}$ The revenue is no longer only scaled by the average feed-in tariff, $F I T\left(k_{i}\right)$, but by an average of the residential electricity price $p_{i}$ and the average feed-in tariff weighted by the self-consumption share $\alpha_{i}$. However, there may be a limit to self-consumption, from which it is impossible to increase self-consumption by extending capacity any further. I denote this individual threshold as $k_{i}^{c}$, leading to an (individual) maximum amount of self-consumption of $\alpha_{i} \times k_{i}^{c} \times H_{i}$. Capacity additions beyond this point only receive the level of the feed-in tariff. Expected revenue can be written as the following piecewise function:

$$
U_{P V}\left(k_{i}\right)=\left\{\begin{array}{ll}
\sum_{t=1}^{T} \beta_{i}^{t}\left(\alpha_{i} k_{i} \times p_{i}+\left(1-\alpha_{i}\right) k_{i} \times F I T\left(k_{i}\right)\right) \times H_{i}, & \text { for } k_{i} \leq k_{i}^{c} \\
\sum_{t=1}^{T} \beta_{i}^{t}\left(\alpha_{i} k_{i}^{c} \times p_{i}+\left(k_{i}-\alpha_{i} k_{i}^{c}\right) \times F I T\left(k_{i}\right)\right) \times H_{i}, & \text { for } k_{i}>k_{i}^{c}
\end{array}\right\}
$$

For the case of the residential electricity price being larger than or equal to the feed-in tariff, i.e. $F I T \leq p,{ }^{42}$ it is important to differentiate whether the individual specific self-consumption capacity limit $k_{i}^{c}$ is located in the smaller or in the larger size class, i.e. $k_{i}^{c}>k^{\prime}$ or $k_{i}^{c} \leq k^{\prime}$. For the former case, i.e. $k_{i}^{c}>k^{\prime}$, marginal benefits are piecewise constant for all levels of capacities $k_{i}:{ }^{4}$

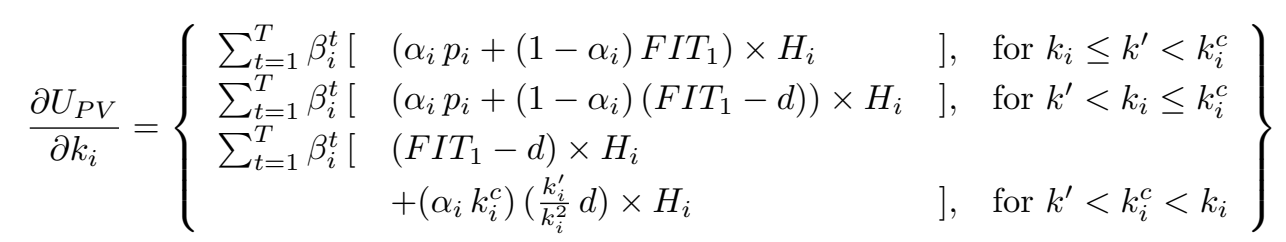

For systems in the smaller size class and with capacity lower than their self-consumption threshold capacity, i.e. $k_{i} \leq k^{\prime}<k_{i}^{c}$, marginal benefit depends on the average of the residential electricity price and the marginal feed-in tariff for the smaller size class weighted by the self-consumption share $\alpha_{i}$. For systems in the larger size class but below their self-consumption threshold, i.e. $k^{\prime}<k_{i} \leq k_{i}^{c}$, the constant benefit decreases compared to a system in the smaller size class as now the lower marginal feed-in tariff of the larger size class $F I T_{1}-d$ appears in the calculation of the weighted average. An interesting case is the marginal benefit for systems in the larger size class that are above their self-consumption threshold capacity, i.e. $k^{\prime}<k_{i}^{c}<k_{i}$. The marginal benefit for systems in the larger size class is higher compared to the situation in which the level of feed-in tariffs is greater than the electricity price. For the latter, the marginal benefit equals

\footnotetext{
${ }^{41}$ I assume that both parameters are fixed over time to maintain tractability of the model.

${ }^{42}$ For the case of $F I T=p$, I assume that households decide to self-consume part of the generated electricity.

${ }^{43}$ The derivations of all marginal benefit expressions presented in this section can be found in Appendix B.
} 
only the first part of the sum, i.e. $\sum_{t=1}^{T} \beta_{i}\left[\left(F I T_{1}-d\right) \times H_{i}\right]$. In the case of self-consumption, there is an additional positive term, which results in a larger marginal benefit. The share that is self-consumed $\left(\alpha_{i} k^{c}\right)$ reduces the negative impact of the decreasing average feed-in tariff. This can be seen by the term $\left(k^{\prime} / k^{2}\right) d$, which equals the absolute value of the derivative of the average feed-in tariff function with respect to capacity for capacities in the larger size class.

When the individual threshold capacity is in the smaller size class, i.e. $k_{c} \leq k^{\prime}$, marginal benefits are somewhat symmetric to the former case. The only difference is for systems that are in the smaller size class but larger than the self-consumption threshold. In this case, the marginal benefit is the same as in the situation where feed-in tariffs are larger than residential electricity prices:

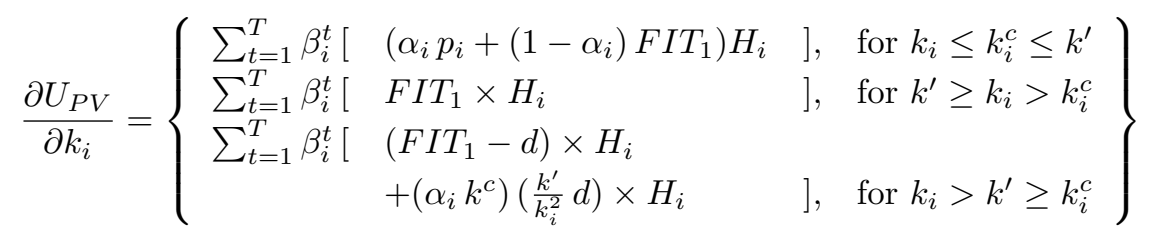

The individual specific self-consumption threshold capacities introduce another form of discontinuities in the marginal benefit function. As an illustrative example, Figure 8 depicts a situation in which the individual threshold capacity is in the smaller size class (in this case at five $\mathrm{kW}$, i.e. $\left.k_{i}^{c}=5 \mathrm{~kW}\right)$.

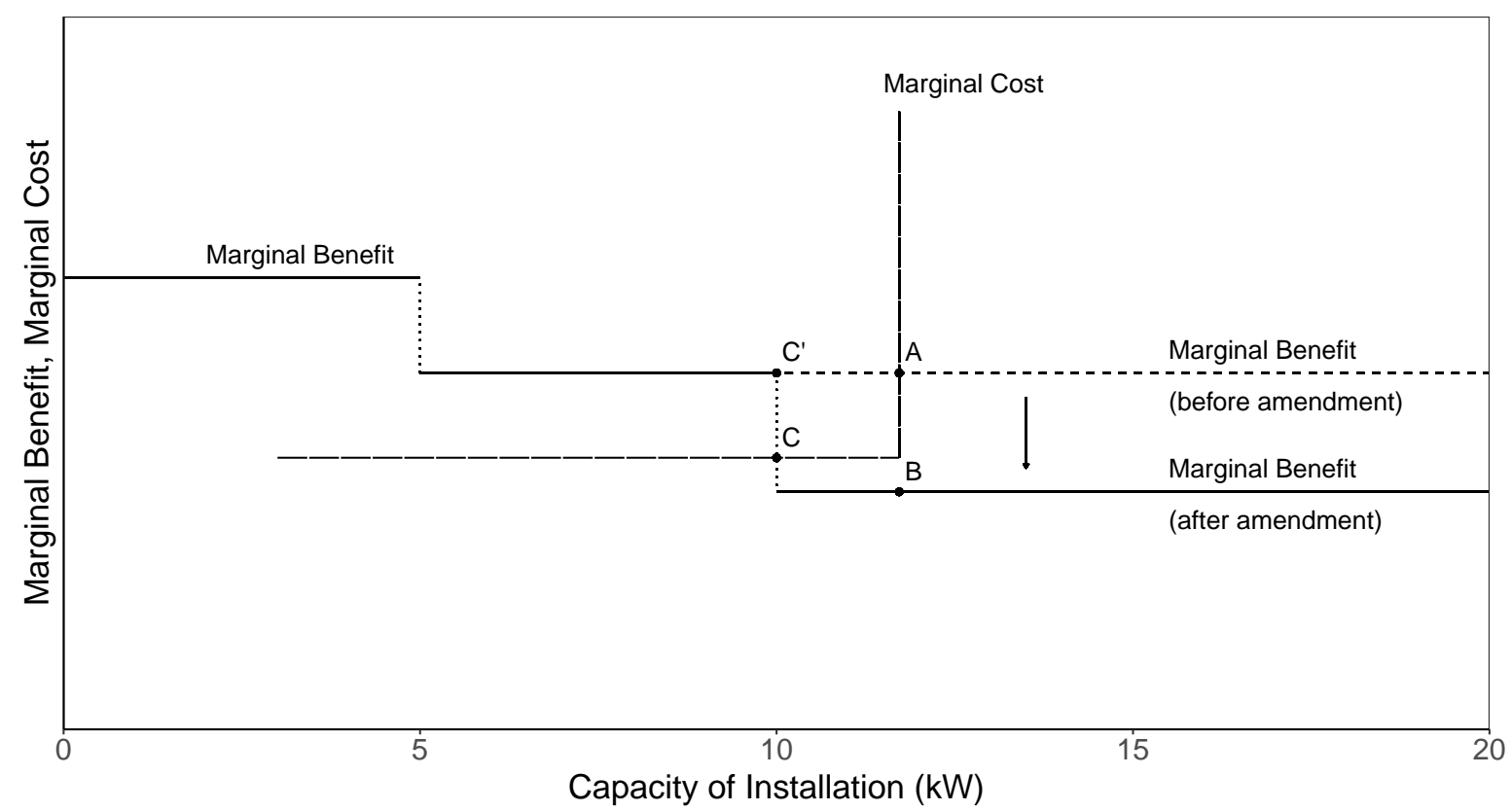

Figure 8: Bunching after Re-evaluation of Size Classes for $F I T<P$ 
When residential electricity prices are higher than the feed-in tariffs, two changes occure: First, the individual self-consumption threshold introduces a household specific discontinuity. As for the household specific marginal cost function (denoted by $M C_{i}$ ) with individual rooftop sizes, they potentially shape adoption decisions. However, as those discontinuities are individual specific, drawn from a joint distribution function $f\left(k_{i}^{c}, M C_{i}\right)$, they should not lead to systemic excess bunching (as evident at the size class border). ${ }^{44}$ Second, the marginal benefit for larger systems is higher compared to the case of electricity prices being lower than the feed-in tariff, although the gap to the smaller size class remains. ${ }^{45}$ The excess bunching observed under differentiated tariffs may be a conservative estimate of the effect of a reduction in marginal feed-in tariffs by five per cent (compared to a situation in which feed-in tariffs are larger than the residential electricity end-use price).

Compared to the model outlined in Section 3, this model extends the influencing factors for the optimal individual capacity choice by the household specific share of self-consumption and the self-consumption threshold capacity:

$$
k_{i}^{*}=f\left(\beta_{i}, F I T, H_{i}, \alpha_{i}, k_{i}^{c}, M C_{i}\right) .
$$

The individual decisions on the installation size can again be aggregated over all $J$ households to obtain total capacity in the different size classes:

$$
K_{0}=\sum_{i}^{J} k_{i} \mathbb{1}\left[k_{i} \leq k^{\prime}\right] \quad \vee \quad K_{1}=\sum_{i}^{J} k_{i} \mathbb{1}\left[k_{i}>k^{\prime}\right],
$$

where $K_{0}$ and $K_{1}$ are aggregate capacity in the smaller and in the larger size class, respectively.

\footnotetext{
$\overline{{ }^{44} \text { Although some capacity choices at } 10 \mathrm{~kW} \text { may }}$ driven by these factors, if either rooftop size or the self-consumption threshold is at $10 \mathrm{~kW}$.

${ }^{45}$ This gap can be seen by rearranging the expression in the square bracket in case 3 to $F I T_{1}-\left(1-\alpha_{i}\left(k^{c} k^{\prime}\right) / k_{i}^{2}\right) d$, in which the second term is positive for $k_{i}>k^{\prime} \geq k_{i}^{c}$.
} 


\section{Appendix B Theoretical Model - Derivations}

This part of the appendix provides the necessary derivations for the results of the theoretical model in Section 3 and Appendix A.

1) FIT $>p_{i}$ and $k_{i} \leq k^{\prime}$. For the case of the feed-in tariff being larger than the residential electricity price, i.e. $F I T>p_{i}$, and for capacities $k_{i}$ in the smaller size class, i.e. $k_{i} \leq k^{\prime}$, the average feed-in tariff remains constant $F I T\left(k_{i}\right)=F I T_{1}$. Its derivative equals zero, i.e. $\partial F I T / \partial k=0$. The marginal benefit of the PV system, i.e. the first derivative of expected returns with respect to capacity, equals:

$$
\begin{aligned}
\frac{\partial U_{P V}}{\partial k} & =\sum_{t=1}^{T} \beta_{i}^{t}\left[\frac{\partial F I T}{\partial k} \times k_{i} H_{i}+F I T\left(k_{i}\right) \times H_{i}\right] \\
& =\sum_{t=1}^{T} \beta_{i}^{t}\left[F I T_{1} \times H_{i}\right]
\end{aligned}
$$

2) FIT $>p_{i}$ and $k_{i}>k^{\prime}$. For the case of the feed-in tariff being larger than the residential electricity price, i.e. $F I T>p_{i}$, and for capacities $k_{i}$ in the larger size class, i.e. $k_{i}>k^{\prime}$, the average feed-in tariff is a capacity weighted average of marginal feed-in tariff of the smaller size class $F I T_{1}$ and of the larger size class $F I T_{2}=F I T_{1}-d$ :

$$
\begin{aligned}
F I T\left(k_{i}\right) & =\frac{k^{\prime}}{k_{i}} F I T_{1}+\frac{k_{i}-k^{\prime}}{k_{i}} F I T_{2} \\
& =\frac{k^{\prime}}{k_{i}} F I T_{1}+\left(F I T_{1}-d\right)-\frac{k^{\prime}}{k_{i}}\left(F I T_{1}-d\right) \\
& =\left(F I T_{1}-d\right)+\frac{k^{\prime}}{k_{i}} d \\
& =F I T_{1}-\left(1-\frac{k^{\prime}}{k_{i}}\right) d
\end{aligned}
$$

The average feed-in tariff decreases with capacity $F I T\left(k_{i}\right)=F I T_{1}-\left(1-k^{\prime} / k_{i}\right) d$ and is lower than the average in the small size class $F I T_{1}$. The derivative with respect to capacity is negative, i.e. 
$\partial F I T / \partial k=-k^{\prime} / k_{i}^{2} d$. The marginal benefit of the PV system, i.e. the first derivative of expected returns with respect to capacity, equals:

$$
\begin{aligned}
\frac{\partial U_{P V}}{\partial k} & =\sum_{t=1}^{T} \beta_{i}^{t}\left[\frac{\partial F I T}{\partial k} \times k_{i} H_{i}+F I T\left(k_{i}\right) \times H_{i}\right] \\
& =\sum_{t=1}^{T} \beta_{i}^{t}\left[-\frac{k^{\prime}}{k_{i}} d \times k_{i} H_{i}+\left(F I T_{1}-\left(1-\frac{k^{\prime}}{k_{i}}\right) d\right) \times H_{i}\right] \\
& =\sum_{t=1}^{T} \beta_{i}^{t}\left[-\frac{k^{\prime}}{k_{i}^{2}} d \times k_{i} H_{i}+\left(F I T_{1}-\left(1-\frac{k^{\prime}}{k_{i}}\right) d\right) \times H_{i}\right] \\
& =\sum_{t=1}^{T} \beta_{i}^{t}\left[\left(F I T_{1}-d\right) \times H_{i}\right]
\end{aligned}
$$

3) $F I T \leq p_{i}$ and $k_{i} \leq k^{\prime}<k_{i}^{c}$. For the case of the feed-in tariff being smaller than or equal to the residential electricity price, i.e. $F I T \leq p_{i}$, for capacities $k_{i}$ in the smaller size class and the self-consumption threshold being in the larger size class, i.e. $k_{i} \leq k^{\prime}<k_{i}^{c}$, the expected revenue of the solar PV system equals $\sum_{t=1}^{T} \beta_{i}^{t}\left(\alpha_{i} k_{i} \times p_{i}+\left(1-\alpha_{i}\right) k_{i} \times F I T_{1}\right) \times H_{i}$. The derivative of this expression with respect to capacity is:

$$
\frac{\partial U_{P V}}{\partial k}=\sum_{t=1}^{T} \beta_{i}^{t}\left[\left(\alpha_{i} \times p_{i}+\left(1-\alpha_{i}\right) \times F I T_{1}\right) \times H_{i}\right]
$$

4) $F I T \leq p_{i}$ and $k^{\prime}<k_{i} \leq k_{i}^{c}$. For the case of the feed-in tariff being smaller than or equal to the residential electricity price, i.e. $F I T \leq p_{i}$, for capacities $k_{i}$ in the larger size class but below or equal to the self-consumption threshold, i.e. $k^{\prime}<k_{i} \leq k_{i}^{c}$, the expected revenue of the solar PV system dependent on its size equals $\sum_{t=1}^{T} \beta_{i}^{t}\left(\alpha_{i} k_{i} \times p_{i}+\left(1-\alpha_{i}\right) k_{i} \times F I T\left(k_{i}\right)\right) \times H_{i}$. The derivative of this expression with respect to capacity is:

$$
\begin{aligned}
\frac{\partial U_{P V}}{\partial k} & =\sum_{t=1}^{T} \beta_{i}^{t}\left[\left(\alpha_{i} \times p_{i}+\left(1-\alpha_{i}\right) \times F I T\left(k_{i}\right)+\left(1-\alpha_{i}\right) k_{i} \times \frac{\partial F I T\left(k_{i}\right)}{\partial k}\right) \times H_{i}\right] \\
& =\sum_{t=1}^{T} \beta_{i}^{t}\left[\left(\alpha_{i} \times p_{i}+\left(1-\alpha_{i}\right) \times\left(F I T_{1}-\left(1-\frac{k^{\prime}}{k_{i}}\right) d\right)+\left(1-\alpha_{i}\right) k_{i} \times\left(-\frac{k^{\prime}}{k_{i}^{2}} d\right)\right) \times H_{i}\right] \\
& =\sum_{t=1}^{T} \beta_{i}^{t}\left[\left(\alpha_{i} \times p_{i}+\left(1-\alpha_{i}\right) \times\left(F I T_{1}-d\right)+\left(1-\alpha_{i}\right) \times \frac{k^{\prime}}{k_{i}} d-\left(1-\alpha_{i}\right) \times \frac{k^{\prime}}{k_{i}} d\right) \times H_{i}\right] \\
& =\sum_{t=1}^{T} \beta_{i}^{t}\left[\left(\alpha_{i} \times p_{i}+\left(1-\alpha_{i}\right) \times\left(F I T_{1}-d\right)\right) \times H_{i}\right]
\end{aligned}
$$


5) $F I T \leq p_{i}$ and $k^{\prime}<k_{i}^{c}<k_{i}$. For the case of the feed-in tariff being smaller than or equal to the residential electricity price, i.e. $F I T \leq p_{i}$, for capacities $k_{i}$ in the larger size class and above the self-consumption threshold, i.e. $k^{\prime}<k_{i}^{c}<k_{i}$, the expected revenue of the solar PV system dependent on its size equals $\sum_{t=1}^{T} \beta_{i}^{t}\left(\alpha_{i} k_{i}^{c} \times p_{i}+\left(k_{i}-\alpha_{i} k_{i}^{c}\right) \times F I T\left(k_{i}\right)\right) \times H_{i}$. The derivative of this expression with respect to capacity is:

$$
\begin{aligned}
\frac{\partial U_{P V}}{\partial k} & =\sum_{t=1}^{T} \beta_{i}^{t}\left[\left(F I T\left(k_{i}\right)+\left(k_{i}-\alpha_{i} k_{i}^{c}\right) \times \frac{\partial F I T\left(k_{i}\right)}{\partial k}\right) \times H_{i}\right] \\
& =\sum_{t=1}^{T} \beta_{i}^{t}\left[\left(\left(F I T_{1}-\left(1-\frac{k^{\prime}}{k_{i}}\right) d\right)+\left(k_{i}-\alpha_{i} k_{i}^{c}\right) \times\left(-\frac{k^{\prime}}{k_{i}^{2}} d\right)\right) \times H_{i}\right] \\
& =\sum_{t=1}^{T} \beta_{i}^{t}\left[\left(\left(F I T_{1}-d\right)-\frac{k^{\prime}}{k_{i}} d+\frac{k^{\prime}}{k_{i}} d+\alpha_{i} k_{i}^{c} \frac{k^{\prime}}{k_{i}^{2}} d\right) \times H_{i}\right] \\
& =\sum_{t=1}^{T} \beta_{i}^{t}\left[\left(\left(F I T_{1}-d\right)+\left(\alpha_{i} k_{i}^{c}\right)\left(\frac{k^{\prime}}{k_{i}^{2}} d\right)\right) \times H_{i}\right]
\end{aligned}
$$

6) $F I T \leq p_{i}$ and $k_{i}^{c} \leq k_{i} \leq k^{\prime}$. For the case of the feed-in tariff being smaller than or equal to the residential electricity price, i.e. FIT $\leq p_{i}$, for capacities $k_{i}$ in the smaller size class but below or equal to the self-consumption threshold, i.e. $k_{i}^{c} \leq k_{i} \leq k^{\prime}$, the expected revenue of the solar PV system equals $\sum_{t=1}^{T} \beta_{i}^{t}\left(\alpha_{i} k_{i} \times p_{i}+\left(1-\alpha_{i}\right) k_{i} \times F I T_{1}\right) \times H_{i}$. The derivative of this expression with respect to capacity is:

$$
\frac{\partial U_{P V}}{\partial k}=\sum_{t=1}^{T} \beta_{i}^{t}\left[\left(\alpha_{i} \times p_{i}+\left(1-\alpha_{i}\right) \times F I T_{1}\right) \times H_{i}\right]
$$

7) $F I T \leq p_{i}$ and $k_{i}^{c}<k_{i} \leq k^{\prime}$. For the case of the feed-in tariff being smaller than or equal to the residential electricity price, i.e. $F I T \leq p_{i}$, for capacities $k_{i}$ in the smaller size class and above the self-consumption threshold, i.e. $k_{i}^{c}<k_{i} \leq k^{\prime}$, the expected revenue of the solar PV system equals $\sum_{t=1}^{T} \beta_{i}^{t}\left(\alpha_{i} k_{i}^{c} \times p_{i}+\left(k_{i}-\alpha_{i} k_{i}^{c}\right) \times F I T_{1}\right) \times H_{i}$. The derivative of this expression with respect to capacity is:

$$
\frac{\partial U_{P V}}{\partial k}=\sum_{t=1}^{T} \beta_{i}^{t}\left[F I T_{1} \times H_{i}\right]
$$

8) $F I T \leq p_{i}$ and $k_{i}^{c} \leq k^{\prime}<k_{i}$. For the case of the feed-in tariff being smaller than or equal to the residential electricity price, i.e. FIT $\leq p_{i}$, for capacities $k_{i}$ in the larger size class and above the self-consumption threshold, i.e. $k_{i}^{c} \leq k^{\prime}<k_{i}$, the expected revenue of the solar PV system dependent on its size equals $\sum_{t=1}^{T} \beta_{i}^{t}\left(\alpha_{i} k_{i}^{c} \times p_{i}+\left(k_{i}-\alpha_{i} k_{i}^{c}\right) \times F I T\left(k_{i}\right)\right) \times H_{i}$. The derivative of this expression with respect to capacity is equivalent to Equation 23. 


\section{Appendix C Estimation of Bin Weights Before and After the PV Amendment}

To underpin the visual inspection of the capacity distribution in Section 2.1 and the theoretical analysis, I examine for which capacity bins these changes are indeed statistically significantly different before and after the enactment of the PV Amendment. I estimate the following equation for the period from January 2009 to July 2012 and from July 2012 to December 2013 separately:

$$
K_{i, m, y, k}=\sum_{k=1}^{20} w_{k}+\mu_{i}+\mu_{m, y}+\epsilon_{i, m, y, k},
$$

where $K_{i, m, y, k}$ is the installed capacity in bin $k$ in county $i$ in month $m$ and year $y$. $w_{k}$ are parameters for a set of binary variables indicating the 20 different one $\mathrm{kW}$ bins. $\mu_{i}$ and $\mu_{m, y}$ are county and month-year fixed effects, respectively.

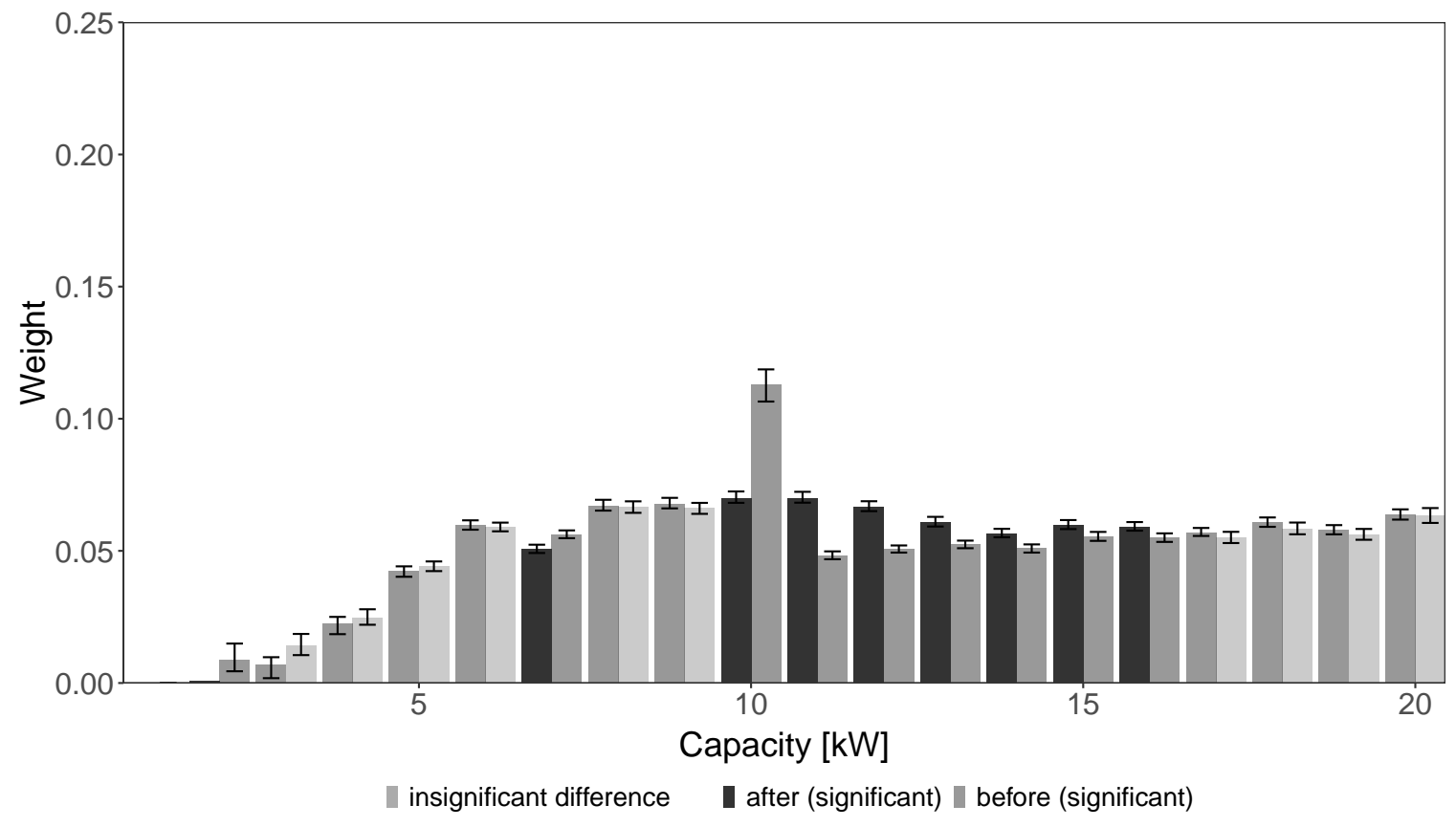

Figure 9: Bin Weights Before and After the PV Amendment

Notes: The darker bars indicate the estimated centred weights $\left(\left(\widehat{w}_{k}-\min \left(\widehat{w}_{k}\right)\right) /\left(\sum_{k=1}^{20} \widehat{w}_{k}-\min \left(\widehat{w}_{k}\right)\right)\right.$ for the time after the PV Amendment, whereas the brighter bars indicate the respective weights before the PV Amendment. Light grey and dark bars within one bin are not statistically significantly different from each other at the one per cent level.

I use the parameter estimates $\widehat{w}_{k}$ to construct weights of the different bins shown in Figure 9 as follows: $\left(\left(\widehat{w}_{k}-\min \left(\widehat{w}_{k}\right)\right) /\left(\sum_{k=1}^{20} \widehat{w}_{k}-\min \left(\widehat{w}_{k}\right)\right) \cdot{ }^{46}\right.$ I perform a wild bootstrap with 999 replications

\footnotetext{
${ }^{46}$ I centre weights by the smallest estimate, which is the one $\mathrm{kW}$ bin with almost no deployment as can also be seen in Figure 3.
} 
to construct 99 per cent confidence intervals for these point estimates. The estimated weights for the bins exhibit a spike at $10 \mathrm{~kW}$ after the PV Amendment and show smaller weights for bins larger than $10 \mathrm{~kW}$ compared to before. However, differences for bin weights before and after the PV Amendment are statistically significant at the one per cent level only for the bins at two and seven $\mathrm{kW}$ (positive) as well as from 10 to $16 \mathrm{~kW}$ (negative), with the largest differences being observed from 11 to $14 \mathrm{~kW}$. The statistical analysis seems to support the hypothesis derived from visual inspection, i.e. bunching at $10 \mathrm{~kW}$ seems to occur from the right. In particular, it suggests that some of the $10 \mathrm{~kW}$ installations would have most likely been built larger (mainly up to $16 \mathrm{~kW}$ ) in absence of the size class re-evaluation. 


\section{Appendix D Cost Development and Differences across Installation Sizes}

Benedetti (2014) present the cost development across different installations sizes with data for the Italian market. In Figure 10, module and inverter prices for different installation sizes experienced similar developments in the recent past. This data can also be informative for the German market since module and inverter prices are pegged to world market prices (IE Leipzig, 2011; ZSW, 2014).

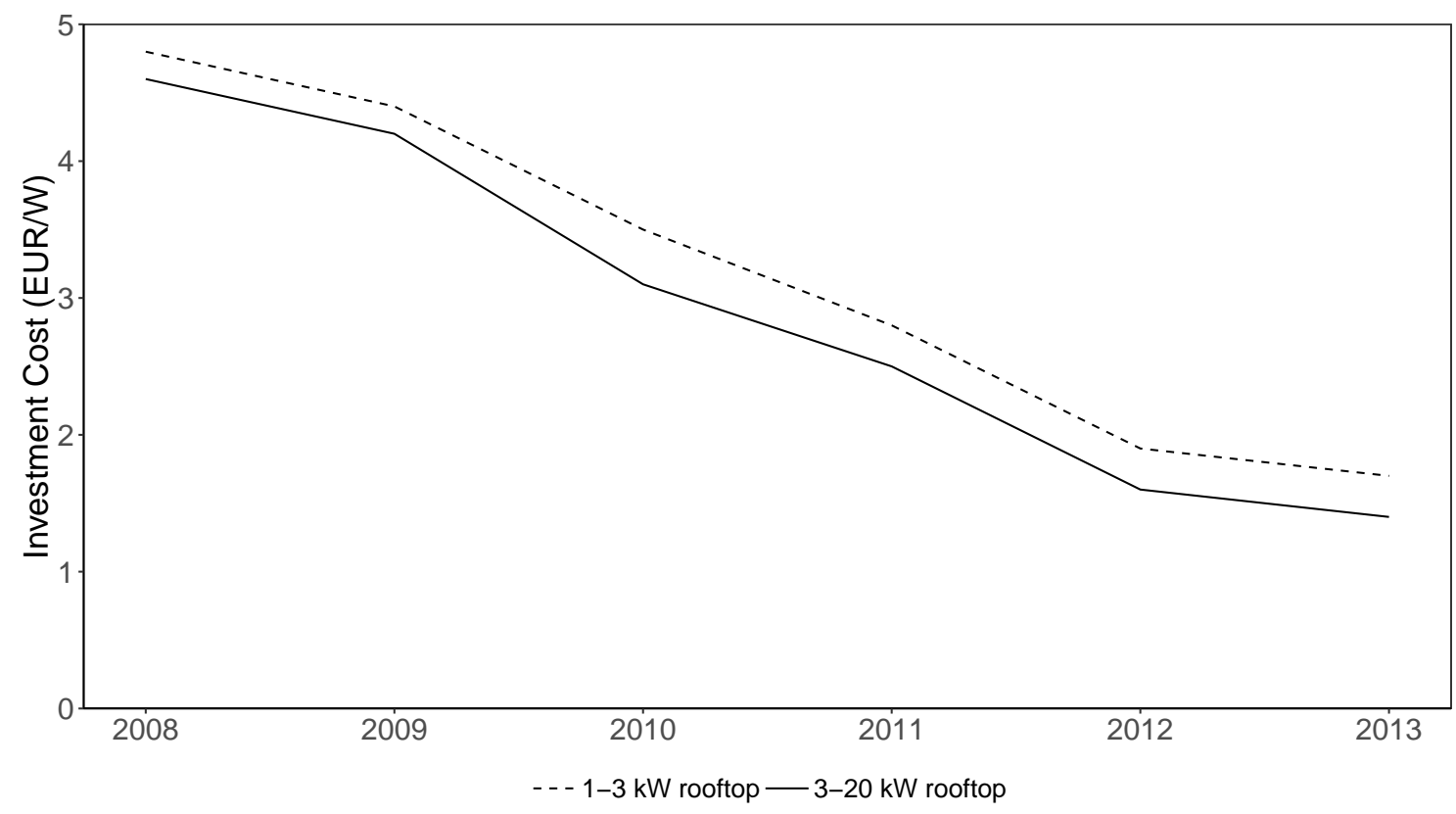

Figure 10: Cost Development for Modules and Inverters for Different Sizes in Italy

Notes: Own illustration based on data from Benedetti (2014). 